\title{
16. PALEOMAGNETISM OF BASEMENT ROCKS, LEG 37
}

\author{
James M. Hall and Patrick J.C. Ryall', \\ Department of Geology, Dalhousie University, Halifax, Nova Scotia, Canada
}

\begin{abstract}
Close to 400 semioriented subsamples of oceanic basement rocks from DSDP Sites 332, 333, 334, and 335 have been tested for paleomagnetic properties. Eight nonbasaltic samples consist of a variety of plutonic rocks from a mélange penetrated at Site 334. Basalt in situ remanence intensity, giving unit weight to each 9.5meter core length, is very close to $40 \times 10^{-4} \mathrm{emu} / \mathrm{cm}^{3}$, or $40 \%$ of the value normally assumed in model studies. The ratio of remanent to induced magnetization is high, averaging 37 . In terms of remanent intensity and induced magnetization, the basalts fit the requirements of the Vine-Matthews hypothesis. However, in terms of vertical polarity layering, and abundant very shallow, nondipole NRM inclinations at Sites 332 and 333, they do not fit the hypothesis. Equivalent magnetic source layer thickness varies from 570 to 820 meters for dipole NRM inclinations to in excess of $2.5 \mathrm{~km}$ for the observed shallow inclinations. Systematic alternating field NRM analysis results in significant inclination change in $44 \%$ of samples. Shallow original magnetization is confirmed for many samples from Sites 332 and 333 . The explanation appears to lie between tectonic tilting or recording of an excursion of long duration of the geomagnetic field.

Cleaned magnetic inclinations are tightly grouped when divided on the basis of lithologic units. However, in many cases, sequences of lithologic/magnetic units have indistinguishable (or nearly so) average cleaned inclinations (the magnetic superunits of this chapter), suggesting formation during single eruptions or short $\left(\sim 10^{2} \mathrm{yr}\right)$ eruptive episodes. It seems that a $2-\mathrm{km}$-thick section of oceanic layer 2 could be formed by about 20 major eruptions or eruptive episodes, together with some minor intrusives. The occurrence of many anomalous inclinations does not permit reliable absolute plate motion estimates to be obtained from the data.
\end{abstract}

\section{INTRODUCTION}

Our knowledge of the geological evolution of the oceanic basins, and in fact, of the plate structure and kinematics of the outer part of the earth, is based on the oceanic linear magnetic anomaly patterns more than on any other single property of the earth. These patterns now have been identified and assigned ages over some $75 \%$ of the ocean basins, yet without any firm knowledge of their source. While it is sensibly pragmatic to use a geological feature without understanding it, experience dictates that advantages will accrue from such an understanding. It is not just a matter of testing our model for the evolution of ocean crust, although some surprises are likely in that direction, but of determining as yet unknown properties of the ocean crust, which, for example, may have important implications for the mode of formation of the crust and its subsequent alteration.

\footnotetext{
'Now at School of Physics, Universiti Sains Malaysia, Minden, Pulau Pinang, Malaysia.
}

It was with this philosophy that DSDP Leg 37 was conceived. As the second DSDP leg to be given deep basement penetration as the prime objective and the first to be sited in an area of well-developed linear magnetic anomalies, we anticipated magnetic results with a wide range of implications.

The major problems regarding the magnetism of the ocean crust appeared to be: (1) Is there a strongly magnetized upper section of crustal layer 2 which is responsible for the linear magnetic anomaly patterns, as modeling studies suggested? (2) What is the thickness and average intensity of magnetism of this section? Various lines of evidence suggested that such a layer might be expected to be between 400 and 500 meters in thickness and to have an average intensity of magnetization of $100 \times 10^{-4} \mathrm{emu} / \mathrm{cm}^{3}$. How closely does reality match this prediction? (3) What is the nature of the lower limit of such a magnetic source layer? Is it sharp or gradational; the result of change in volcanic style (extrusive versus intrusive perhaps) or of increase in metamorphic grade with depth? (4) Are the paleomagnetic directions recorded in the magnetic source layer capable of giving reliable estimates of ab- 
solute plate motions, in addition to the linear anomaly patterns giving relative plate motions?

\section{SITES, SAMPLING, MEASUREMENT TECHNIQUE}

The DSDP Leg 37 drilling sites were located along a sea-floor spreading flow line extending from the Median Valley of the Mid-Atlantic Ridge in the project FAMOUS survey area into the American plate (fig. 5 , Chapter 2, this volume). Magnetic surveying by CSS Hudson and Glomar Challenger in the vicinity of the flow line indicated that a well-developed linear magnetic anomaly pattern was present, and a composite magnetic profile along the flow line is shown in fig. 5, Chapter 2 (this volume). Anomalies 1 to 5 inclusive were identified by matching the form of the profile with the time-magnetic polarity zones of Talwani et al. (1971). The prime site, 332, located in the sediment pond nearest to the Median Valley containing a minimum of 100 meters of sediment, lies in the negative anomaly between positive anomalies 2 and 3 . The estimated age of the corresponding reverse geomagnetic polarity interval is 3.32 to $3.78 \mathrm{~m}$.y. A plot of anomaly crossover points of known age with distance along the flow line (fig. 8, Chapter 2, this volume) defines an excellent straight line. The equivalent spreading rate is $1.17 \pm 0.05 \mathrm{~cm} / \mathrm{yr}$ between 0.69 and 11 m.y.B.P. and the apparent age of Site 332, based on its position along the profile, is $3.50 \pm 0.10$ m.y. Fig. 9 (Chapter 2, this report) shows the detail of the part of the anomaly pattern in the vicinity of Sites 332 and 333, which has the same apparent age as Site 332 , together with profiles through the sites showing their clear location within the negative anomaly (fig. 10, Chapter 2, this volume). Site 334 was located in a sediment pond at the base of an east-facing escarpment. It appears to be located on the younger flank of magnetic anomaly 5 (fig. 3 , Chapter 4 , this volume), and an age of 8.9 m.y. is obtained by interpolation. Beyond the prominent negative anomaly immediately to the west of anomaly 5 the magnetic anomaly pattern, while still lineated, does not match the continuation of the timemagnetic polarity sequence of Heirtzler et al. (1968). Site 335 was selected at the base of an east-facing escarpment in an attempt to match the topographic conditions at Site 334. The magnetic anomaly, in which Site 335 is located is negative (fig. 2, Chapter 5, this volume). By assuming that the spreading rate of 1.17 $\mathrm{cm} / \mathrm{yr}$ calculated for anomalies 1 to 5 holds for 5 to 6 , an estimated age of $16.5 \mathrm{~m} . \mathrm{y}$. is obtained for basement at the site. Subsequently, both radiometric and paleontological ages for basement at this site suggest that the age is slightly less, at 10.5 to 14.0 m.y. and $14.5 \pm 1.0$ (S.D. of the mean), respectively. An increase in spreading rate or a tectonic break must occur between Sites 334 and 335 .

Sampling of the recovered basement core followed exactly the techniques developed on Leg 34 (Ade-Hall and Johnson, 1976a,b), with semioriented minicores drilled transversely to the main core at selected locations. Routine samples, taken at regular intervals, were designated " $\mathrm{A}$ " (thin section, geochemical and paleomagnetic subsample) and "B" (velocity and paleomagnetic subsample). Additional minicores were taken wherever extra paleomagnetic information was desirable. In retrospect the criticism of the shipboard paleomagnetic sampling is one of the operators rather than the sequence of operations. Demagnetization and other tests indicate that a number of critical samples were certainly, probably, or possibly inverted at some point in the sampling sequence. For this reason we recommend that on future basement legs core orientation and paleomagnetic sampling be carried out by one person only, preferably the person also making the paleomagnetic measurements, and that sufficient time be allocated for sampling to allow every step to be double-checked.

Paleomagnetic measurements were made both on Glomar Challenger and at Dalhousie University. The large recovery of basement material on Leg 37 led to a policy of reconnaissance measurements in the form of partial demagnetization being done on the ship followed by full remanence analysis at Dalhousie University. As a result of a fault in the shipborne demagnetizing unit some problems occurred in matching ship and shore data. During Leg 37 the shipboard paleomagnetic laboratory consisted of a Schonstedt SSM-1a analog output spinner magnetometer together with a Dalhousie-built alternating-field demagnetization unit. The continuation of measurements at Dalhousie University involved the use of a Schonstedt DSM-1 digital spinner magnetometer, which is interfaced with a PDP11/05 computer and another Dalhousie-built demagnetizing unit. Initial susceptibility measurements were made using a Geophysical Specialties MS-3 magnetic susceptibility bridge.

\section{RESULTS}

\section{In Situ Magnetization of Basement Rocks}

Here we are concerned with the magnetic state of the in situ basement rocks at the Leg 37 sites. This is of intrinsic interest, but is of greater interest in testing the assumptions of the Vine-Matthews hypothesis for the origin of the linear magnetic anomaly patterns observed over the world's oceans. That is, the anomalies are supposed to be associated with long narrow prisms of oceanic crust where the magnetism is dominantly a stable remanence representing the polarity state of the geomagnetic dipole field at the time of crustal formation.

The in situ magnetization of rocks can be attributed to three physical mechanisms, which must, to some extent, overlap in their action: (1) Stable thermal remanence, for igneous rocks, is acquired during initial cooling (TRM) and subsequently may be modified by various alteration processes giving rise to observed NRM. The time constants for the relaxation of stable remanence at near ambient temperatures range from a few years, or perhaps less, to greater than the age of the earth. (2) Viscous remanence (VRM) grows logarithmically with time when an igneous rock is exposed to a steady magnetic field, its decay on removal of the field follows a similar law. VRM acquisition varies widely in suboceanic igneous rocks (Lowrie, 1974; Ade-Hall and Johnson, 1976a,b). In some coarse- 
grained rocks VRM probably comprises all of the NRM while in many fine-grained basalts it is effectively absent from the NRM. (3) Induced magnetization appears essentially instantaneously on application of a field, and disappears as quickly on removal of the field. Induced magnetization may be envisioned as that part of the viscous magnetization spectrum with relaxation times short enough for magnetization to follow a $60-\mathrm{Hz}$ oscillating field with negligible phase lag.

In this section we describe the NRM of basement samples, together with induced magnetization. Viscous magnetization acquisition for the samples is described elsewhere in this volume (Ryall and Ade-Hall, in preparation).

\section{In Situ NRM Intensities}

The intensity of stable remanence (NRM) varies widely in the basalts, ranging from $2.45 \times 10^{-4}$ to $176 \times$ $10^{-4} \mathrm{emu} / \mathrm{cm}^{3}$. The average basalt intensity, giving unit weight to each 9.5 -meter core length, is very close to 40 $\times 10^{-4} \mathrm{emu} / \mathrm{cm}^{3}$ (Ade-Hall et al., 1975b). Core average NRM intensities and directions are given in Chapters 25 (this volume) and Figures 1 and 2 . Two features are significant; short wavelength variations of NRM intensity with depth, occurring over distances of up to several tens of meters, and the lack of overall trends in NRM intensity with depth. Short wavelength changes in NRM intensity with depth can be correlated with variation in petrological nature and alteration state. These relationships are described in Hall and Ryall (Chapter 23, this volume). The lack of an overall trend NRM intensity with depth is of interest in view of the geophysical and geochemical models of oceanic crustal layer 2 , which invoke a 400 - to 500-meter-thick strongly magnetized uppermost section and a steep temperature gradient, with concomitant metamorphism (and presumably change in NRM intensity) with depth. Our results indicate that neither of these models apply, at least in the vicinity of the Leg 37 sites. An uppermost magnetic layer is likely to be significantly thicker than 500 meters on the average, at least at two of the sites, and high temperature gradients, if they occur, must be of rather localized distribution. Thus, the present temperature at 550 meters subbasement in Hole 332B is only $14.5^{\circ} \mathrm{C}$, and there is no evidence for significantly higher temperatures having occurred in the past. We prefer a model where at least the upper quarter of layer 2 has a temperature distribution and resulting alteration as a function of water convection, with broad areas of slowly downwelling cold sea-water and much more limited areas of rapid upwelling of hot water, perhaps expressed by hot springs on the sea floor. In this model high temperatures at shallow depths, metamorphism, and a strong depth dependence of magnetic properties on depth will only occur within the limited areas of hot water upwelling.

NRM intensities for the components of the mélange of intrusive rocks penetrated at Site 334 are again very variable, ranging from what would be typical values for the basalts at this and other Leg 37 sites to values very much lower than recorded for any basalt sample (Table 4 , Chapter 4 , this volume).

\section{In Situ NRM Inclinations}

For a description of basalt NRM inclinations it is sensible to divide the results from the five Leg 37 holes into two groups, the first consisting of Sites 334 and 335 , and the second of Holes 332A, 332B, and 333A.

At Sites 334 and 335 basalt magnetic inclinations are closely confined with mean values very near to the ideal dipole field inclination of $\pm 56^{\circ}$ for the present latitudes of the sites (Figure 2). Thus, at Site 334 the mean NRM inclination for 18 samples is $+52.6 \pm 2^{\circ}$ (RMS error of the mean), and at Site 335 the mean NRM inclination for 42 samples is $-63.5 \pm 1^{\circ}$.

The situation in Holes 332A, 332B, and 333A is more complex than at Sites 334 and 335 with wide ranges of NRM inclinations including many values that deviate strongly from the ideal dipole inclinations, which again are all close to $\pm 56^{\circ}$ (Figure 1). In Hole 332A a 60meter normally magnetized zone overlies basalts of generally reverse inclinations but with most values very much shallower than ideal dipole inclinations. Shallow reverse magnetization inclinations dominate the Hole 332B section, the normal zone of 332A being missing although Holes 332A and 332B are separated laterally only by 107 meters. Occasional normally magnetized samples occur within the long shallow reversely magnetized sections of Holes $332 \mathrm{~A}$ and 332B. In Hole $333 \mathrm{~A}$ all basalts and allied rocks have very shallow NRM inclinations, some being upwards and others downwards.

Components of the mélange of intrusive rocks sampled at Site 334 show wide variation in NRM inclination from +04 to -77 . However, there is a distinct bias towards upwards inclinations (5 of 6 samples), which is in marked contrast to the uniform downwards inclinations of the overlying basalts.

The wide occurrence of nonideal dipole NRM inclinations in the basalts from the Leg 37 sites could result from the action of several mechanisms. The simplest is that the combinations of original reverse polarity dipole inclinations, plus VRM acquired during the present Brunhes Normal polarity epoch, has produced shallow inclined resultants. There are several arguments against this explanation. In particular, atypically steep as well as shallow inclinations would be expected to be seen in such a large collection of samples. Again, shallow inclinations were recorded for many very fine grained basalts. From experience elsewhere this type of magnetic material is known to acquire negligible VRM. This question of the possible presence of secondary components can be settled by alternating-field NRM analysis, and the results of the application of this technique are given in a following section.

\section{In Situ Induced Magnetization}

The induced magnetization of the Leg 37 basement rocks has been obtained from the product of initial susceptibility, $k$, and the ambient field in the area of the sites, taken as 0.45 oe from USNOO chart H.O. 1703. In paleomagnetic work and magnetic anomaly interpretations the ratio of remanent to induced magnetization, $Q$, is of more interest than $k$ alone (Chapters 2-5, 


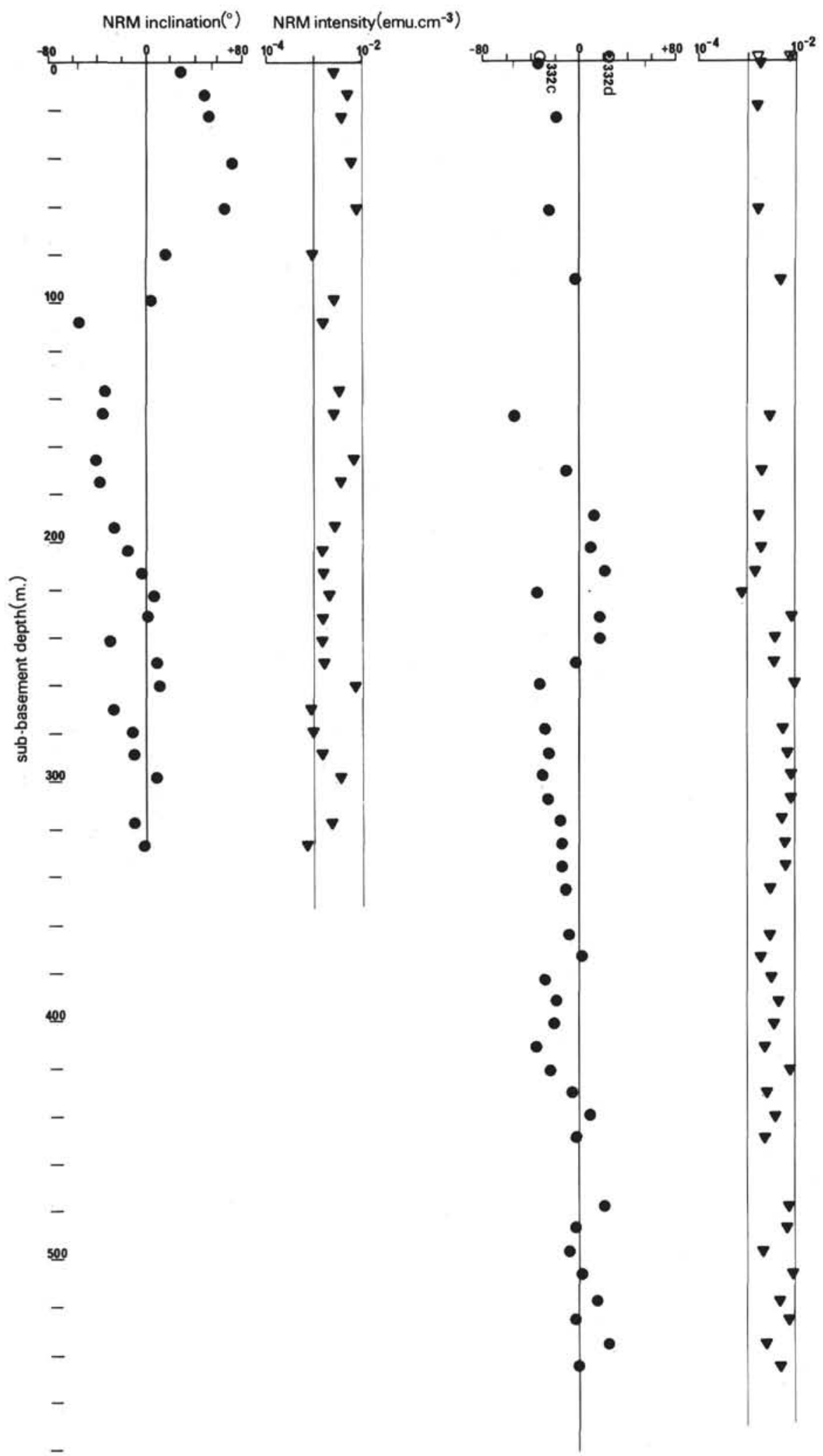

Hole 332 A

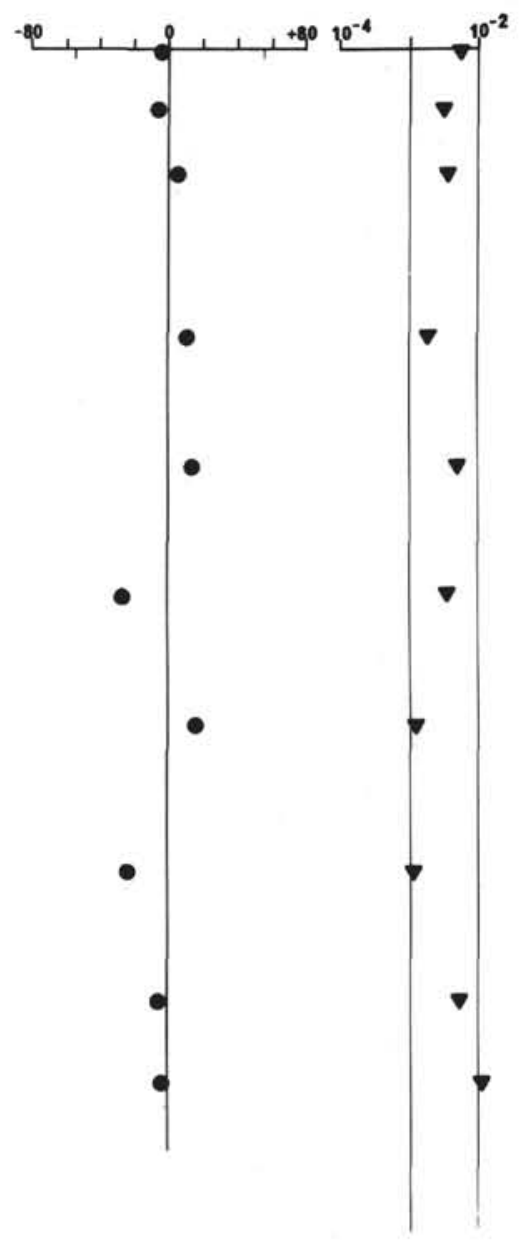

Figure 1. Depth distributions of NRM inclination and intensity, averaged over 9.5-meters core lengths, for Holes 332A, 332B, and $333 A$.

this volume). A high $Q$ value implies that remanence dominates the magnetization of a sample, and a low $Q$ that induced magnetization dominates. For the Leg 37 basalts in general $Q$ is always high, ranging from 3 to 188 , with $66 \%$ of values with $Q \geq 19$, i.e., remanence accounts for $95 \%$ or more of the sum of remanent and in- 


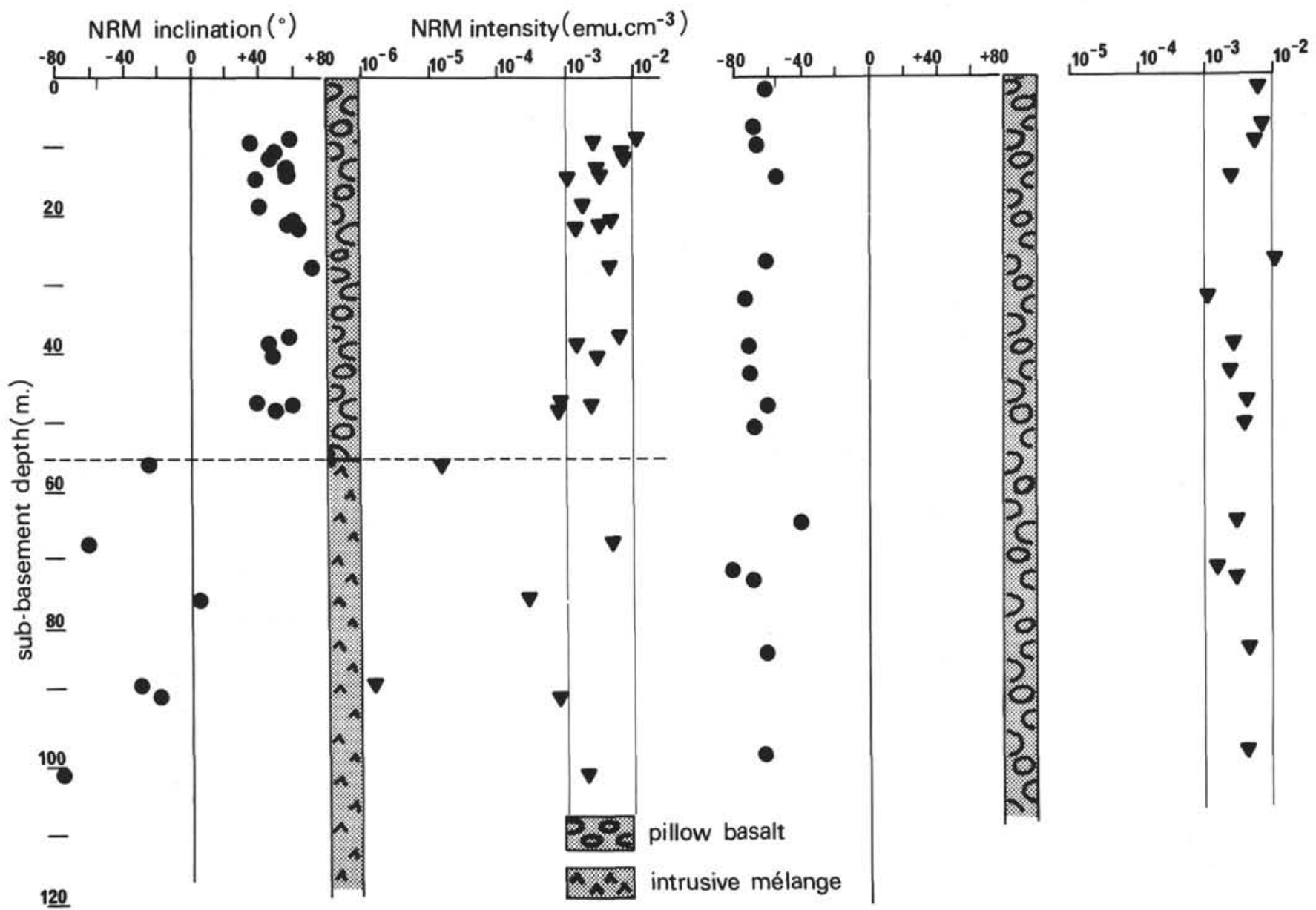

Figure 2. Depth distributions of NRM inclination and intensity, averaged over 9.5-meters core lengths, for Sites 334 and 335.

duced magnetization (Figures 3a, 4). In contrast, for the components of the mélange of intrusives penetrated at Site 334, $Q$ averages only 2.5 (Figure $3 \mathrm{~b}$ ). Distributions of $Q$ for each site (Figure 4) show that high values are typical of every basalt section. No simple variation of $Q$ with depth is seen in any basalt section, although at Site 335 there is a suggestion of regular decrease with depth from 58 for the top 25meter interval to 44 for the 75 to 100 meter interval (Figure 5). $Q$ varies irregularly in the deep holes of Sites 332 and 333 , with peak values for 25 -meter intervals occurring at intermediate levels in Holes 332A (150-175 $\mathrm{m})$ and 332B (325-350 $\mathrm{m}$ ) (Figure 5).

\section{Upper Layer 2 at the Leg 37 Sites and the Vine-Matthews Hypothesis}

The Leg 37 results provide a unique test of the reality of the predictions of the Vine-Matthews hypothesis (Vine and Matthews, 1963) which supposes that some part of the oceanic crust consists of alternately normally and reversely magnetized prisms, elongate parallel to the strikes of both structural and magnetic anomaly patterns. Vine and Matthews originally suggested a thickness of from 11 to $20 \mathrm{~km}$ for the magnetized layer, the base being bounded by the Curie point isotherm for magnetite. More recently, both "Deep Tow" profiles over topographic features and measurements of the NRM intensity of dredge-haul samples of basalt, have led to the widely accepted assumption that the magnetized layer is best represented as having thickness of 400 or 500 meters and intensity of $100 \times 10^{-4}$ $\mathrm{emu} / \mathrm{cm}^{3}$ (Carmichael, 1970; Irving et al., 1970; Talwani et al., 1971; Atwater and Mudie, 1973; Sclater and Klitgord, 1973). We note that dredge-haul samples are strongly biased in areal distribution to ridge crests and the practice of sampling the less altered interiors of pillows can give values twice as high as the pillow average (Marshall and Cox, 1971b; Ryall and AdeHall, 1975). A more uniformly distributed set of DSDP samples examined by Lowrie et al. (1973) had a much lower average NRM intensity than the dredge-haul samples, and requires a $2.5-\mathrm{km}$-thick layer to account for observed magnetic anomalies. Similarly low intensities for DSDP basalts are reported in Johnson and Ade-Hall (1975).

The within-site average NRM intensities of the Leg 37 basalts, at close to $40 \times 10^{-4} \mathrm{emu} / \mathrm{cm}^{3}$, vary little between sites, with the average value intermediate between results for dredge-haul collections and for older DSDP Atlantic sites reported in Lowrie et al., 

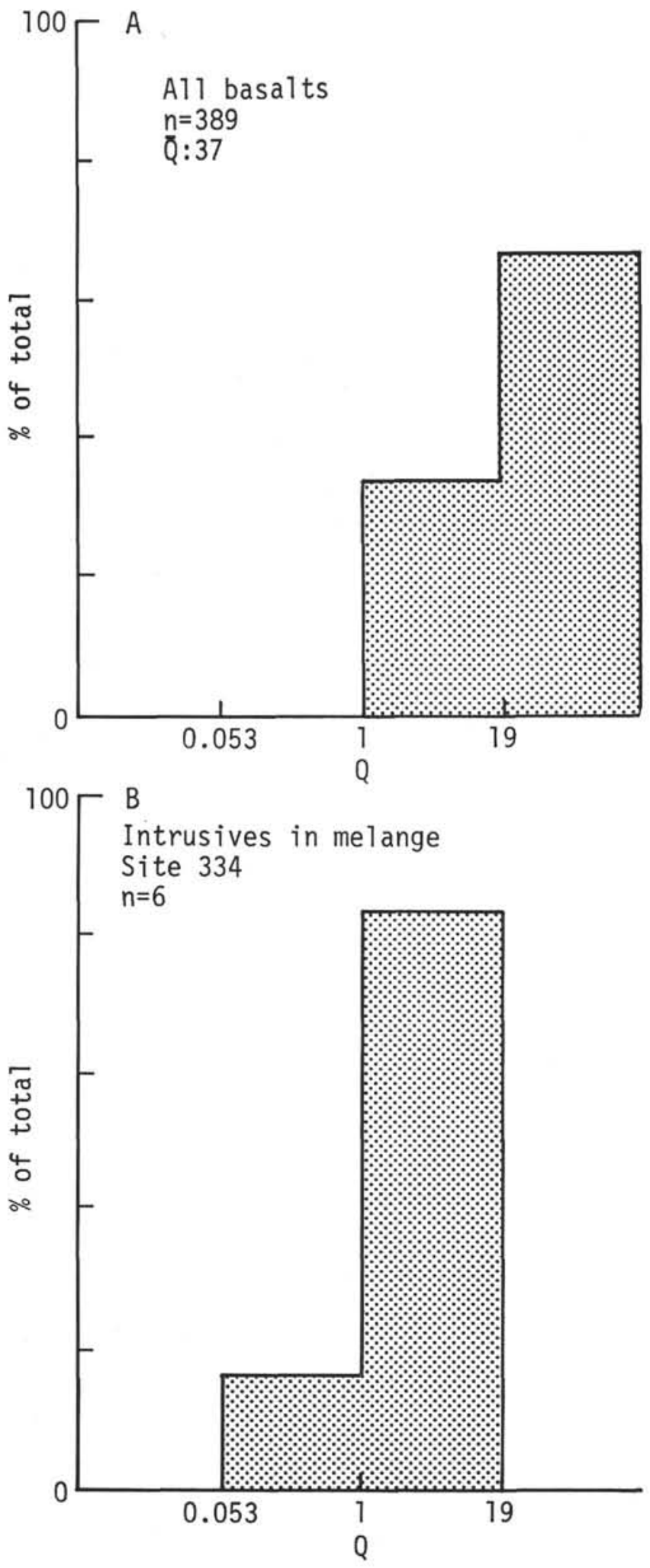

Figure 3. (A) Distribution of Q ratios for Leg 37 basalt samples. (B) Distribution of $\mathrm{Q}$ ratios for intrusive rocks in the melange penetrated at Site 334. (At a $\mathrm{Q}$ ratio of 0.052 only $5 \%$ of the magnetization is remenent, for a ratio of $1.0,50 \%$ of the magnetization is remanent, while at a ratio of $19,95 \%$ of the magnetization is remanent.)
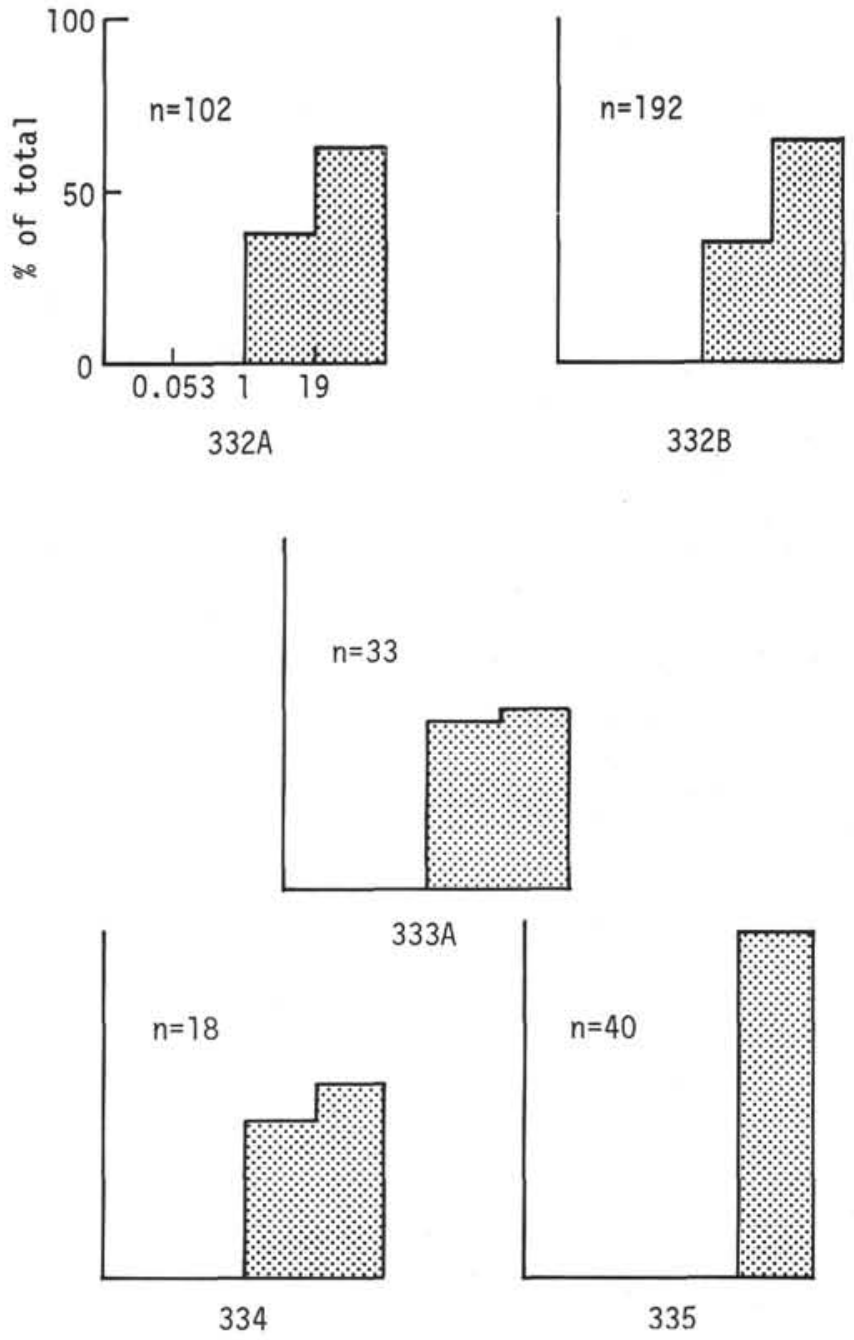

Figure 4. Q ratio distributions for the basalts at each Leg 37 site.

1973. In fact, the site-average NRM intensity for the Leg 37 basalts amounts to only $40 \%$ of the value usually assumed in model studies. To compensate for the observed intensities being less than half of the modeling intensity we might assume that the strongly magnetized layer is proportionately thicker, to a first approximation a layer $1.25 \mathrm{~km}$ in thickness is indicated. This figure lies well within the limit originally suggested by Vine and Matthews and also within the refraction seismic estimate of the average thickness of oceanic crustal layer 2. The lack of a trend in NRM intensity with depth at any site supports a thicker magnetic layer than is usually assumed, although the 500 -meter depth used in modeling was only exceeded in Hole 332B.

The simple model used in computing magnetic anomalies requires that the magnetization of adjacent crustal prisms is dominated by alternately normal and reverse stable remanent magnetization. Two other possible types of magnetization are viscous and induced magnetization. While VRM results are not presently available for our Leg 37 samples, it would be surprising if the VRM contribution were significant in many cases. The high $Q$ values imply that, on the 

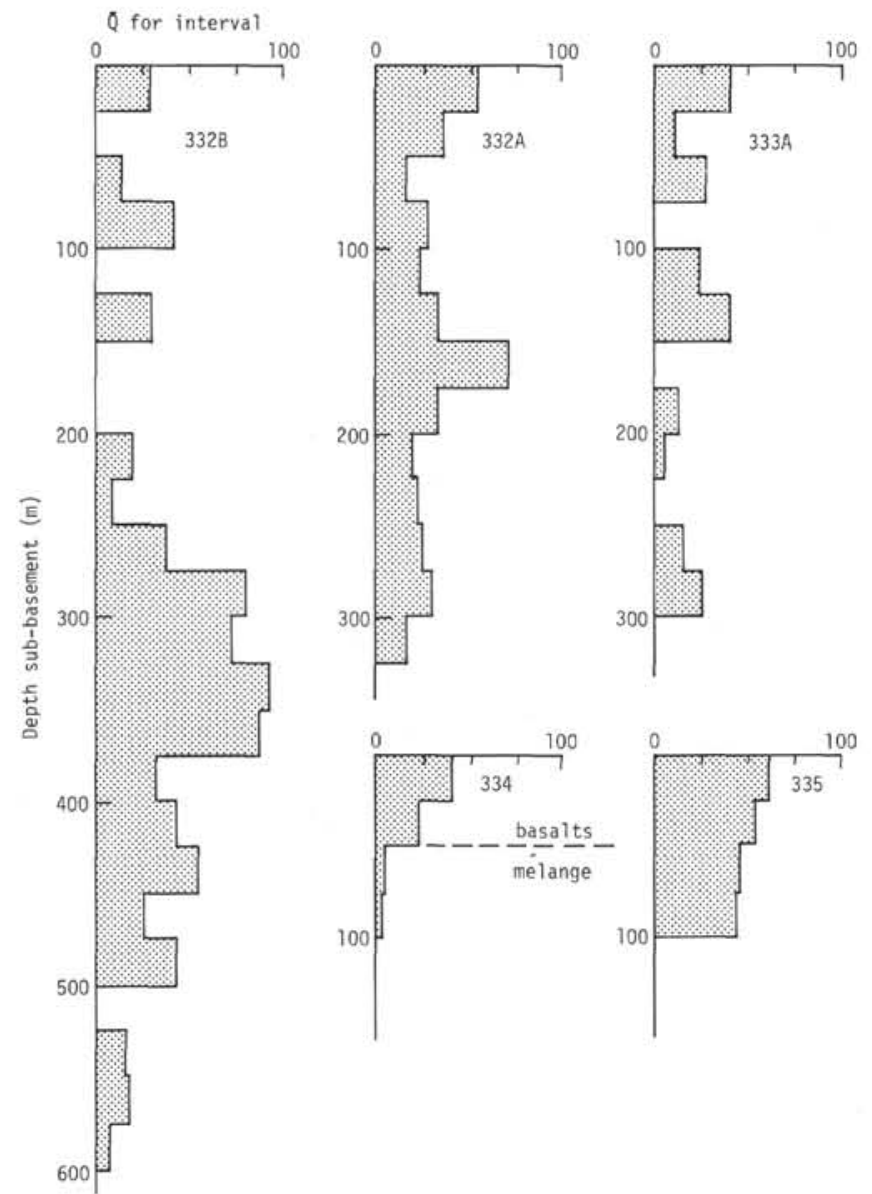

Figure 5. Distribution of average Q ratio with depth for the Leg 37 basement sections.

average, induced magnetization amounts to only $2.6 \%$ of stable remanence, which is a negligible level. Therefore it is reasonable to proceed on the basis that stable NRM is the cause of the anomalies.

The simple model also implies a stable NRM which is not only uniform with depth, but also which is aligned in the direction of the dipole field. Marked deviation from this prediction of the Vine-Matthews hypothesis is seen in NRM inclinations for the younger Sites 332 and 333 . Here we see at least one and perhaps several polarity reversals recorded in what, by the hypothesis, is expected to be a uniformly reversely magnetized prism. Again most NRM inclinations are very much shallower than the inclination for an ideal dipole field, which begs questions on the reality of the simple magnetization process proposed in the hypothesis. Atwater and Mudie (1973) have modified the simple model of Vine and Matthews to allow for a finite width for the zone of formation of new crust and a finite time for polarity reversals to occur. Our results indicate that further complicating features must be taken into account; in new models of the magnetic part of the ocean crust vertical polarity zoning and magnetic directions well away from the ideal dipole field inclination will have to be incorporated.

The presence of plutonic rocks within what has been assumed to be a volcanic layer is also of significance here. The magnetic properties of the Site 334 plutonic rocks differ from those of the basalts, NRM intensity being generally less, NRM inclinations having the opposite sense from overlying basalts, and induced magnetization being relatively more important than for the basalts.

\section{Anomaly Modeling Using the Observed NRM Properties}

We have used the NRM intensities and directions for the Leg 37 basalts, together with the magnetic anomaly amplitudes observed on the sea-floor spreading flow line on which the drilling sites are located (fig. 1, Chapter 1, this volume), to calculate the thickness of the uniformly magnetized source layer needed to produce the anomaly amplitudes. We have assumed that a spreading rate of $1.17 \mathrm{~cm} / \mathrm{yr}$ applies everywhere along the flow line. There are several alternatives regarding choice of intensities and inclinations. Although the average NRM intensity, giving unit weight to each 9.5meter core length, is very close to $40 \times 10^{-4} \mathrm{emu} / \mathrm{cm}^{3}$ there are grounds for modeling using a range of intensity values. Thus, penetration by the drill of many apparently soft sections at all sites leads us to suspect the presence of extensive sediment, basalt rubble zones, and cavities, of negligible or zero net magnetization. In addition to weighting the average intensities for sediment, cavity, and rubble zones, consideration must also be given to the inclination of magnetization selected for modeling. At the two older sites, 334 and 335, the inclinations of the basalts are close enough to the ideal dipole field for the present latitudes of the sites to suggest that the NRM inclination for the magnetic source layer as a whole might alternatively be taken as the ideal dipole inclination of $\pm 56^{\circ}$. However, at the younger sites the average inclinations are so far from the dipole field over layer thicknesses of up to 582 meters that dipole field magnetization is not a reasonable alternative. In fact, it is impossible to see how the negative anomaly in which Sites 332 and 333 are located can be produced by the upper part of layer 2. Only a 57-meter-thick sequence of massive picritic pillow basalts in Hole 332B, physically akin to the Site 334 and 335 basalts, with its top at close to 270 meters subbasement, is potential anomaly source material. Here NRM inclination is fairly steeply upwards, averaging $-29^{\circ}$, and intensity relatively high at an average of $67 \times 10^{-4} \mathrm{emu} / \mathrm{cm}^{3}$. Elsewhere either or both intensities and inclinations are generally low, combining to ensure relatively small external magnetic fields.

From the data for the two older sites we have computed magnetic source layer thicknesses using the observed average intensity $\left(40 \times 10^{-4} \mathrm{emu} / \mathrm{cm}^{3}\right)$ and inclination $\left( \pm 60^{\circ}\right)$, together with various combinations involving the weighted average intensity $\left(32 \times 10^{-4}\right.$ $\left.\mathrm{emu} / \mathrm{cm}^{3}\right)$ and ideal dipole field inclination $\left( \pm 56^{\circ}\right)$. Generally convincing fits of observed and computed anomaly profiles are obtained, as, for example, is shown in Figure 6. Depending on the combination of intensities and inclinations selected, a uniformly magnetized source layer would need to be between 570 and 820 meters in thickness. That is, computed layer thickness extends from the usually accepted values of 400 or 500 meters to nearly a factor of two greater. 


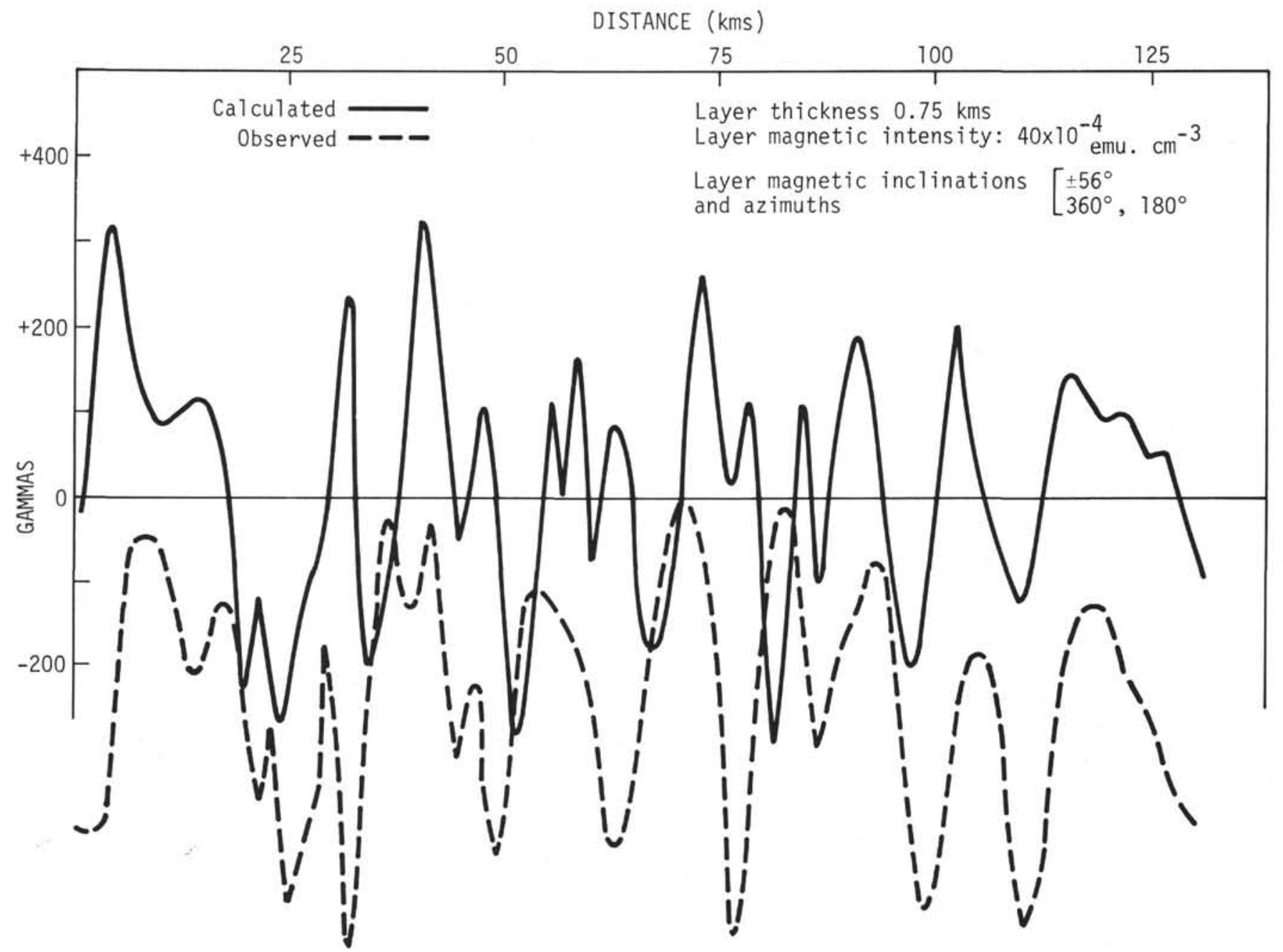

Figure 6. Example of observed and computed magnetic anomaly profiles for the Leg 37 sea-floor spreading flow line from the median valley of the Mid-Atlantic Ridge to anomaly 5.

While these estimates of the thickness of magnetic source layers are based on more representative information than all previous estimates, they still cannot be taken as generally applicable, as is clear from the presence of only 55 meters of basalt at Site 334 and the complicated lithological and magnetic situation at Sites 332 and 333. The lack of a thick basaltic magnetic source layer at Site 334 is surprising since the site is well within a clear example of magnetic anomaly 5 which, after central positive anomaly 1 , is usually the easiest to recognize on all spreading ridge systems.

As expected, profiles generated using the average magnetic properties of the Site 332 and 333 basalts do not resemble the observed magnetic anomaly profile. Using an intensity of $39 \times 10^{-4} \mathrm{emu} / \mathrm{cm}^{3}$ (which is reduced to $21 \times 10^{-4} \mathrm{emu} / \mathrm{cm}^{3}$ if the presence of sediment, cavities, and rubble is allowed for) and an average inclination of $04^{\circ}$, the source layer would have to exceed $2.5 \mathrm{~km}$ in thickness to match the amplitudes (but not the forms) of the observed anomalies. A poor match in anomaly form still results if the R block, in which Sites 332 and 333 are situated, is assigned an inclination of $04^{\circ}$ while elsewhere inclinations are taken as $\pm 60^{\circ}$ and source thickness 570 meters.
There appear to be two ways in which layer 2 in the vicinity of Sites 332 and 333 could produce an appreciable magnetic anomaly. One is if strongly magnetized material, with ideal dipole or steeper inclinations, lies below 600 meters depth within the layer. The other is if magnetization azimuths are well away from the meridian. This would be likely if the shallow NRM inclinations at these two sites represent an excursion of the geomagnetic field from the dipole condition. The recovery of fully oriented cores would be necessary to test this suggestion.

NRM Analysis: Purpose, Technique, Range of Results

The NRM of all samples was routinely partly demagnetized at Dalhousie University using the alternatingfield technique. Routine NRM analysis had several objectives; to characterize samples magnetically, to identify the inclinations of soft and hard components of magnetization, and to look into the geomagnetic, volcanological, and structural implications of the inclinations of these hard and soft components. Alternating-field demagnetization was carried out using a two-axis tumbler designed to reverse its sense of rotation after each rotation of $360^{\circ}$ about the vertical 
axis. In this way the acquisition of rotational remanent magnetization during demagnetization was prevented. Alternating current was supplied to the demagnetizing coil from a brushless $400-\mathrm{Hz}$ motor generator, the motor generator acting as a supply voltage transient attenuator. The NRM of all samples was measured after demagnetization at $0,25,50,75,100,150,200$, $250,300,350,400$, and 500 oe peak field. If more than $30 \%$ of the NRM intensity remained after this routine treatment, demagnetization was continued either until reduction to this level had been achieved or to 1000-oe peak field. The 500-oe maximum value for routine coverage was selected after demagnetization of a pilot group of samples had shown that stable components were always clearly defined by this field. Rapid measurements of partly demagnetized NRMs, with a total of over 5000 measurements, proved possible using a Schonstedt DSM-1 spinner magnetometer. Paper tape printout information from the magnetometer teletape was edited, stored on magnetic tape, and then filed for further treatment using the Dalhousie University CDC 6400 computer. Table 11, Chapter 2 (this volume) is a facsimile of the summary of magnetic data printout from this latter computer. In this section we are most concerned with the $\mathrm{I}(\mathrm{O}), \mathrm{D}(\mathrm{O})$, STABLI, and STABLD columns of this table, where $\mathrm{I}(\mathrm{O})$ and $\mathrm{D}(\mathrm{O})$ are the inclination and declination of the undemagnetized NRM, and STABLI and STABLD the inclination and declination of the stable component of the NRM. The STABLI and STABLD angles were obtained by a computer search of the data for each sample and represent averages of directions occasionally at three or more usually at four demagnetization steps. Values obtained in this way for each sample have been checked by reference to a printout of the complete demagnetization information and in a small number of instances physically preferable values obtained directly from this printout were substituted for the computer selections. While inclinations are referred to the axes of each drill hole, which is known or assumed to be within $5^{\circ}$ of the vertical, declination was arbitrarily assigned to each sample and only changes during demagnetization are of physical significance.

Routine demagnetization yielded a physically satisfactory stable direction for all basement samples with the exception of one basalt and two intrusives. For the basalts, but possibly not for the sediments intercalated within the basement, or for the components of the mélange penetrated at Site 334, stable directions are reasonably interpreted as representing the direction of the ambient magnetic field at the time of formation. Soft components, where present, are interpreted as viscous moments largely, but not always entirely acquired during the present Brunhes Normal epoch.

The behavior of NRMs during demagnetization varied widely. At one extreme are samples where the NRM is essentially single stable component in nature (Figure 7). In this category undemagnetized NRM directions are nearly identical with cleaned directions. However, very small secondary components are evident in the NRM of some samples, $\mathrm{N}$ for the $\mathrm{R}$ sample of 12(c) and possibly $\mathrm{R}$ for the $\mathrm{N}$ sample of $12(\mathrm{~b})$. Thick sequences of pillows characteristically provide material of this type. At the other extreme are samples with very significant or dominant NRM soft components (Figure $8)$. The three samples shown in this figure all have upwards-directed stable components with downwardsdirected soft components. This arrangement is to be expected for samples originally magnetized in a reverse polarity field and subjected to a normal polarity field for the last $7 \times 10^{5} \mathrm{yr}$. In two of these examples the soft downwards inclined component was sufficiently intense to give the undemagnetized NRM a downwards inclination. For the oriented basement basalts as a whole, reversal of the sense of the vertical component of the NRM during demagnetization occurred for 51 samples, or $15 \%$ of the collection, while NRM inclination changed significantly $\left(\Delta \mathrm{I} \geq 5^{\circ}\right)$ during demagnetization for 150 samples or $44 \%$ of the collection. The widespread occurrence of significant soft components in the basement basalts clearly demonstrates the need for routine systematic NRM demagnetization for this type of material before original-cooling ambient magnetic field inclinations can be identified.

On Leg 34 near-vertical soft component inclination appeared to indicate magnetization during drilling or recovery by fields associated with the bottom-hole assembly (Ade-Hall and Johnson, 1976a,b). The use of monel metal lowermost drill collar and core barrel appeared to reduce this drilling magnetization significantly. For this reason Sites 332 and 333 were drilled using monel metal bottom-hole assembly components. This procedure was successful in reducing or preventing drilling magnetization as only three samples (332A-31-3, 70-73 cm (2); 332A-31-3, 79-82 cm (2); and $335-13-2,13-22 \mathrm{~cm}$ ) had soft components inclined at close to the vertical.

\section{ORIGIN OF STABLE DIRECTIONS}

A number of arguments have been presented in the past which strongly suggest that the stable directions of magnetization of oceanic basalts closely represent the direction of the ambient magnetic field during the initial cooling of the basalt (Ryall and Ade-Hall, 1975; Johnson and Ade-Hall, 1975). We present here further evidence from four detailed studies of single cooling units. These thin units must have been magnetized initially over a small time interval of at the most a few years. As a result initially magnetic inclination must have been uniform throughout and, if preserved, in the stable inclinations must show this property. Three of the four units $(1,2$, and 4$)$ show a high degree of internal consistency of stable inclinations (Table 1), supporting the originality of the direction of the stable components of magnetization. Unit 3, in contrast, shows an appreciably greater scatter of stable inclinations, with a range from $-44^{\circ}$ to $+72^{\circ}$. A number of explanations are possible here; magnetization directions may not represent the ambient field during initial cooling, several cooling units may have been sampled, and sample orientation and marking errors may have been made. From NRM behavior during demagnetization of individual samples, it is clear that the last explanation accounts for at least part of the scatter of inclinations, 


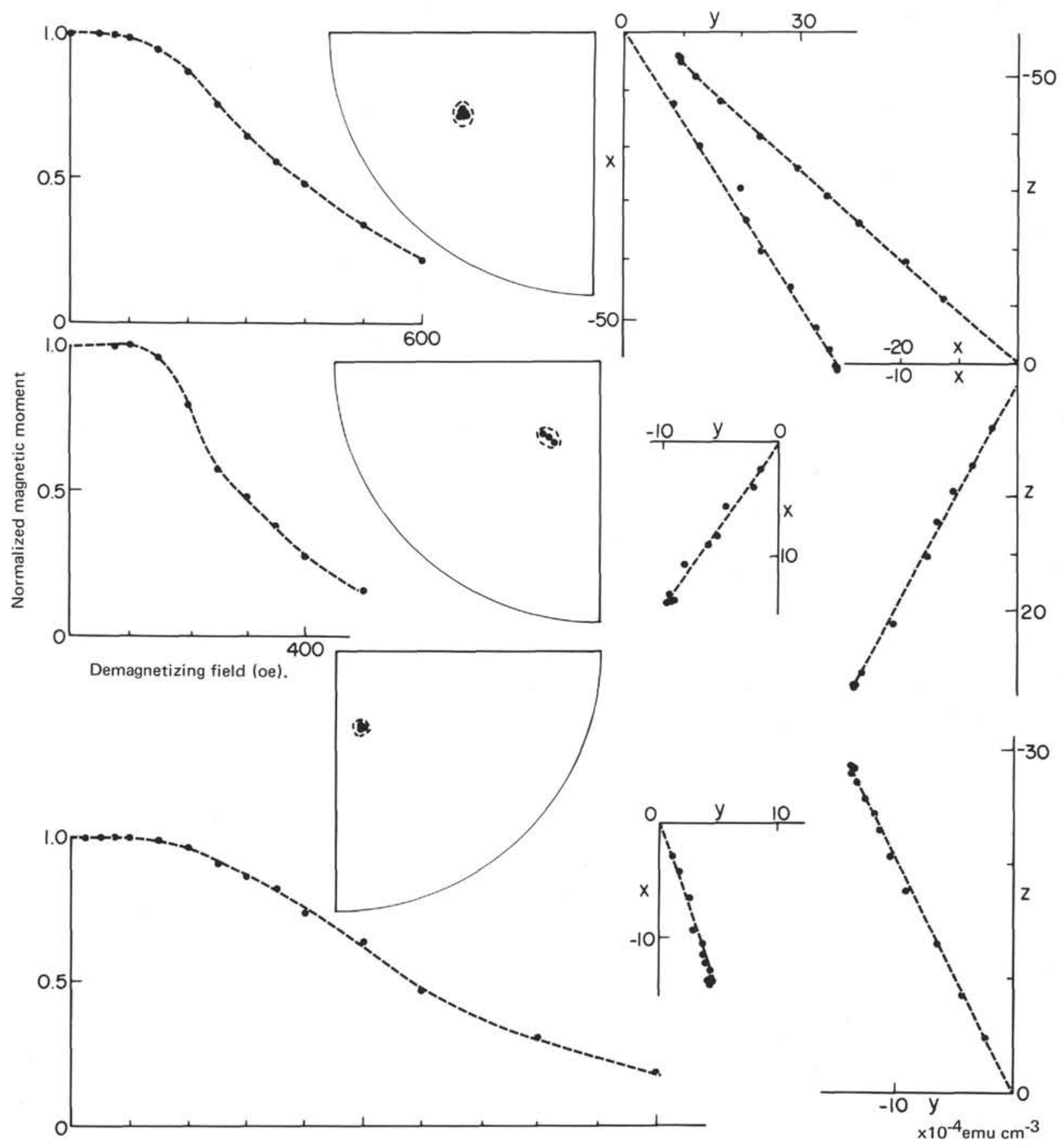

Figure 7. Behavior during alternating field partial demagnetization of typical Leg 37 basalts with stable NRM. From top to bottom the samples illustrated are $332 B-20-1,115-118 \mathrm{~cm}(2) ; 334-16-4,7-10 \mathrm{~cm}(2)$ and $355-6-$ $2,10-12 \mathrm{~cm}$.

and for this reason we have recommended that during IPOD legs only one person be allowed to take oriented samples for paleomagnetic work. Resampling of this unit will be essential in order to eliminate the orientation error contribution to the scatter of inclination.

\section{SPATIAL DISTRIBUTION OF SOFT AND HARD NRM COMPONENTS}

Basalts with significant soft components associated with their NRMs are not distributed randomly throughout the collection. At Sites 333, 334, and 335 soft components are either absent or very uncommon (Figure 9). At Site 332 basalts with large soft NRM components directed at close to the ambient field are restricted to a number of zones; at 300 to 400 meters subbottom in Hole $332 \mathrm{~A}$ and 320 to 400 meters and from 480 meters to the bottom of the hole at 715 meters in Hole 332B (Figure 10). These concentrations of basalts with soft NRM components must be a function of the magnetic history and $\mathrm{Fe}-\mathrm{Ti}$ oxide grain size or oxide composition. 

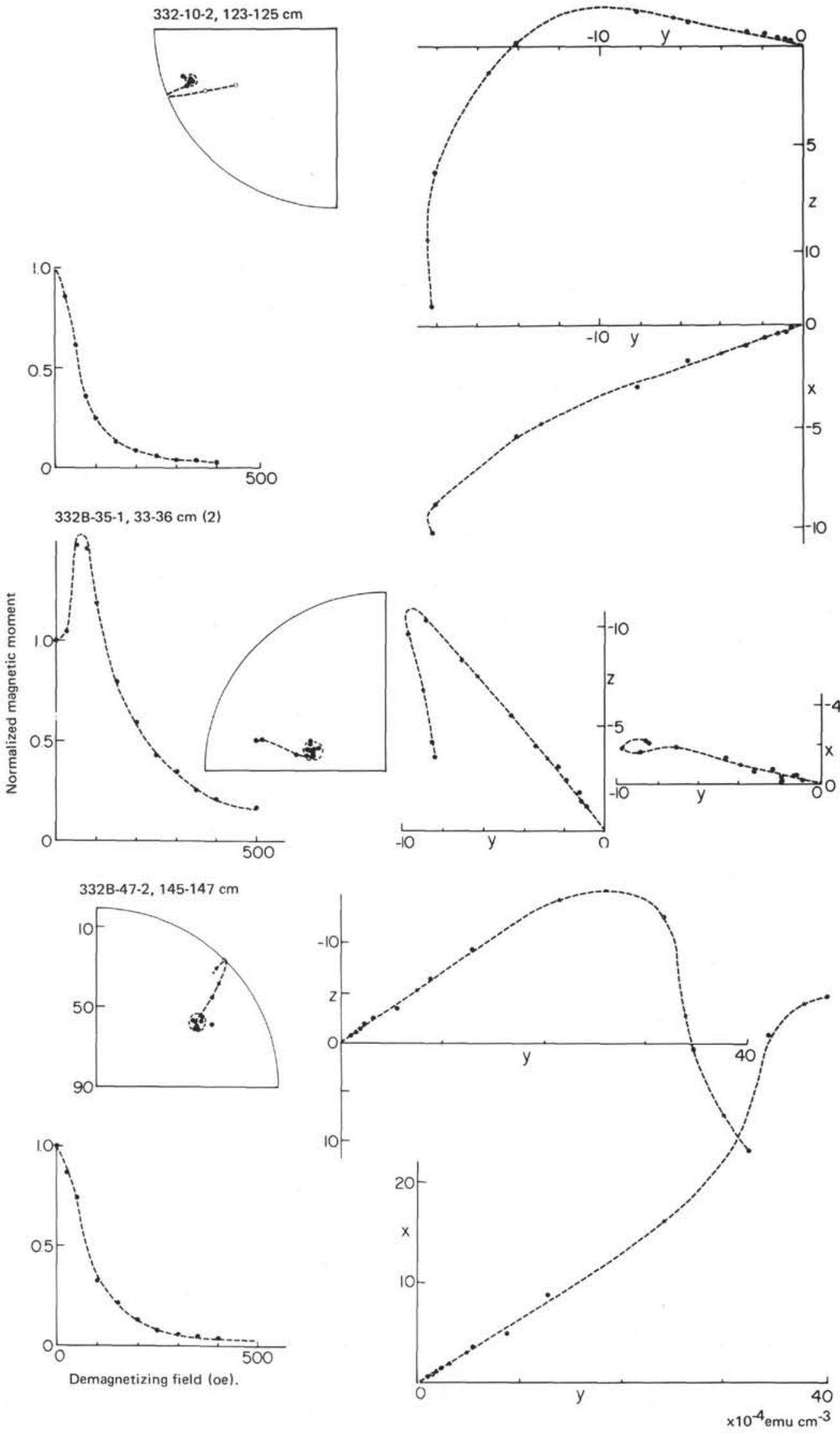

Figure 8. Behavior during alternating-field partial demagnetization of typical Leg 37 basalts with large soft component contribution to the NRM. From top to bottom the samples illustrated are: $332 B-10-2,123-125 \mathrm{~cm} ; 332 B-35-1,33-36 \mathrm{~cm}(2)$; and $332 B-47-2,145-147 \mathrm{~cm}$. 
TABLE 1

Summary of Paleomagnetic Studies on Single Cooling Units

\begin{tabular}{|c|c|c|c|}
\hline $\begin{array}{l}\text { Unit } 1 \\
\text { Feldspar phyric basalt, } \\
\text { Hole 332B, Core } 3 \\
\text { Stable Inclinations }\left({ }^{\circ}\right)\end{array}$ & $\begin{array}{l}\text { Unit } 2 \\
\text { Olivine phyric basalt } \\
\text { Hole } 332 \mathrm{~B} \text {, Core } 35 \\
\text { Stable Inclinations }\left(^{\circ}\right)\end{array}$ & $\begin{array}{c}\text { Unit } 3 \\
\text { Feldspar phyric basalt, } \\
\text { Hole 332B, Core 36, } 37 \\
\text { Stable Inclinations }\end{array}$ & $\begin{array}{c}\text { Unit } 4 \\
\text { Altered basalt pillow } \\
\text { Site } 335 \\
\text { Stable Inclinations }\end{array}$ \\
\hline $\begin{array}{l}-32 \\
-27\end{array}$ & $\begin{array}{l}-46 \\
-46\end{array}$ & $\begin{array}{l}-26 \\
-17\end{array}$ & $\begin{array}{l}-58 \\
-56\end{array}$ \\
\hline $\begin{array}{l}-19 \\
-34 \\
-27 \\
-28 \\
-29 \\
-30 \\
-28 \\
-26 \\
-22\end{array}$ & $\begin{array}{l}-52 \\
-38 \\
-44 \\
-42 \\
-37 \\
-43 \\
-32 \\
-42 \\
-30 \\
-39\end{array}$ & $\begin{array}{l}-05 \\
-01 \\
+03 \\
-07 \\
+07 \\
-06 \\
-38 \\
+72 \\
-17 \\
-16\end{array}$ & $\begin{array}{l}-60 \\
-62 \\
-58 \\
-61 \\
-58 \\
-66 \\
-65 \\
-66 \\
-66 \\
-64\end{array}$ \\
\hline $\begin{array}{l}\text { Average stable inclination: } \\
-27 \pm 1^{\circ} \\
\text { (RMS error of mean) }\end{array}$ & I : $-41 \pm 2^{\circ}$ & $\begin{array}{l}-10 \\
-16 \\
-22 \\
-35 \\
-32 \\
-40 \\
-44\end{array}$ & I : $-62 \pm 1^{\circ}$ \\
\hline
\end{tabular}

\section{STABLE NRM INCLINATIONS (FIGURES 9 AND 10)}

\section{Shallow Inclinations}

The NRM inclinations for the basalts and plutonic rocks recovered during DSDP Leg 37 were in many instances much shallower than the ideal geomagnetic field inclinations of $\pm 56^{\circ}$ for the latitudes of the sites (Ade-Hall et al., 1975a). Such a result could be explained by an appropriate combination of a stable NRM with the inclination of the dipole field and another remanence, a CRM or VRM. The most important result of the systematic demagnetization of NRMs is to show that this explanation is not viable. Thus, while the stable inclinations are generally very much better grouped than the undemagnetized NRM inclinations (Figures 9 and 10), they are frequently still significantly shallower than the ideal dipole inclinations. The magnitude of this disagreement between ideal and observed stable inclinations is evident from the fact that $82 \%$ of the samples have stable inclinations shallower than the present secular variation range of approximately $\pm 10^{\circ}$ about the ideal dipole inclination, while at least $27 \%$ have stable inclinations, which probably lie outside the field of stable $\mathrm{N}$ or $\mathrm{R}$ states of Wilson et al. (1972). Subdividing the collection by holes we see that the shallow stable inclinations are a feature of Holes 332A, B, C, D and 333A, while at Sites 334 and 335 stable inclinations are within the expected secular variation range about the ideal inclination. At Sites 332 and 333 shallow inclinations are characteristic throughout, only a short normal section at the top of $332 \mathrm{~A}$ and scattered samples elsewhere having stable inclinations within the secular variation range about the ideal values.

Several explanations can be proposed for the abundance of shallow stable NRM inclinations at Sites 332 and 333. One explanation, chemical remagnetization during alteration, can be set aside immediately on the grounds that NRM intensity but not direction changes during alteration (Marshall and Cox, 1971a; Ryall and Ade-Hall, 1975; Johnson and Merrill, 1973). The choice then appears to be between tectonic rotation of the section and the recording of atypical geomagnetic conditions. There is no compelling evidence in favor of either explanation. If the tectonic explanation is correct then to bring the stable inclinations from the dipole value to their present shallow level requires a minimum rotation of the sequences at Sites 332 and 333 of from $30^{\circ}$ to $40^{\circ}$, with the dip to the south. Little is known of the detailed tectonics of oceanic layer 2. However, Macdonald et al. (1975) report that fault blocks forming the walls of the Median Valley of the Mid-Atlantic Ridge at $36^{\circ}$ to $37^{\circ} \mathrm{N}$ typically slope outwards, i.e., east or west, at $3^{\circ}$ to $10^{\circ}$. Steep dips in north or south directions were not found. Again, the ideal dipole inclinations of the Normal sequence capping the basement section in Hole 332A mitigates against uniform tectonic rotation of the section as an explanation for the shallow stable inclinations of the deeper basalts.

At first glance explanation of the shallow stable inclinations in terms of atypical geomagnetic field conditions is attractive. It can be envisioned that the shallow inclinations represent a polarity transition between a normal interval, recorded by the units at the top of basement in Hole 332A, and a reverse interval, represented by basalts below the greatest depths reached at Sites 332 and 333. Against this explanation, however, is the fact that in Neogene Icelandic lavas, only $5 \%$ of the flows record polarity transitions. On these grounds it is statistically improbable that two of the four Leg 37 sites penetrated basalts erupted during geomagnetic polarity transitions. Recent work (Lawley, 1970; Wilson and McElhinny, 1974) suggests that sometimes the geomagnetic field spends a significant fraction of time well away from the ideal dipole state 

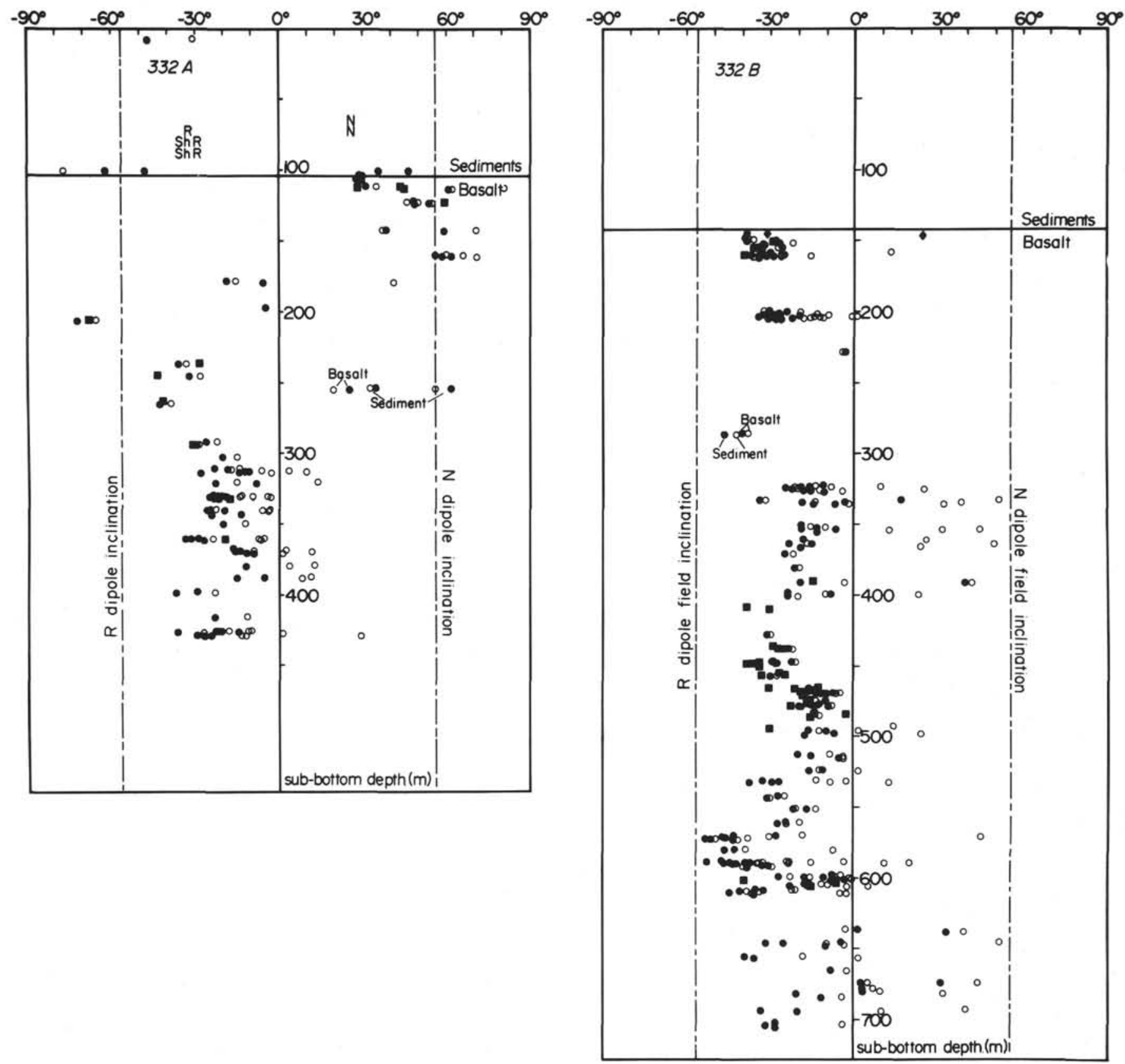

Figure 9. Depth profiles for Holes $332 \mathrm{~A}$ and $332 B$ showing NRM inclinations $(\bullet)$ and stable component inclinations $(\circ)$ for each sample. (-) indicates that NRM and stable inclinations are coincident.

without reversing. Such extended excursions could account for the commonplace shallow stable basalt inclinations at the Leg 37 sites. Until more is known quantitatively of the behavior of the geomagnetic field, the explanation of the commonplace shallow stable basalt inclinations must remain a major problem.

\section{Polarities}

Notwithstanding the shallow stable NRM inclination of many of the basalts it is possible to identify polarities with considerable certainty. That this is possible for only semioriented samples indicates the value of working away from the equatorial zone of near horizontal magnetic inclinations. With the exceptions of the 70-meter-thick normally magnetized zone at the top of the basement succession at Hole $332 \mathrm{~A}$, together with a small number of individual samples, both sections at Site 332 are probably dominantly reversely magnetized. A possible exception is the interval from 666 to 682 meters in Hole 332B. There average stable inclination is almost horizontal. The polarity of the large number of nearly horizontally magnetized samples from Hole $333 \mathrm{~A}$ is also unclear. At Sites 334 and 335 the steep stable basalt NRM inclinations can confidently be interpreted as representing $\mathbf{N}$ and $\mathbf{R}$ magnetization, respectively.

Since basalt stable NRM inclinations represent the state of the geomagnetic field at the time of initial cool- 

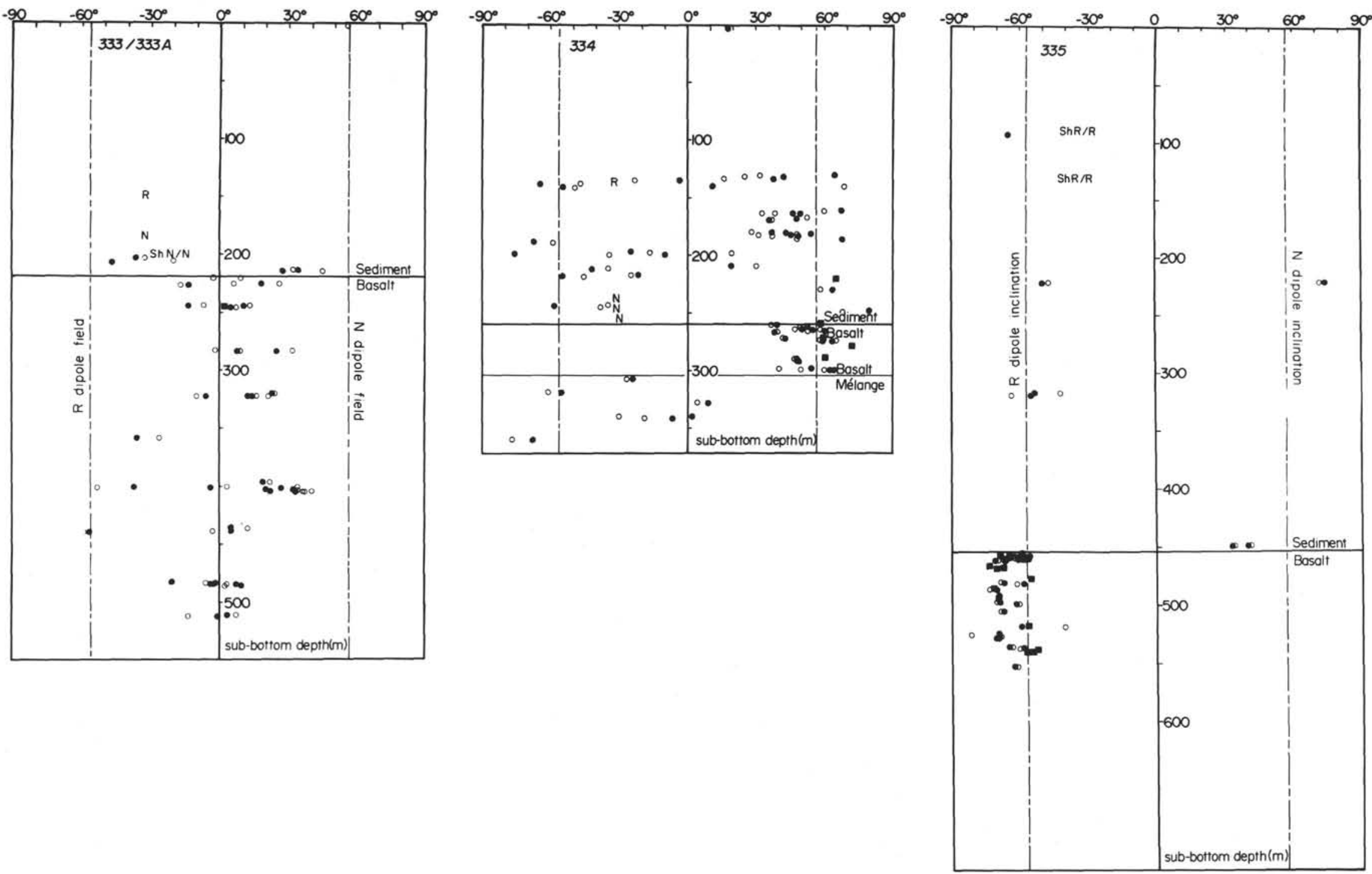

Figure 10. Depth profiles for Holes 333 and $333 A$ and Sites 334 and 335 showing NRM inclinations (O) and stable component inclinations ( $\bullet$ for each sample. (-) indicates that NRM and stable inclinations are coincident. 
ing, we see that the dominant upper basement magnetic polarity at Sites 332,334 , and 335 agrees with the sense of the local anomaly of the linear pattern. However, details of the magnetic polarity structure of the upper section at Site 332, the scattered shallow upwards and downwards inclinations at Site 333 , and the scattered but predominantly upwards directed inclinations of the intrusive mélange of Site 334 are not predicted from the anomaly pattern in the area. The magnetic structure of uppermost oceanic basement at the Leg 37 sites is sufficiently complex to require a more complex model for the generation of magnetic basement than that proposed by Atwater and Mudie (1973), which allows for continuous spreading, a finite width for the zone of formation of new crust, and a finite time for polarity reversals. The Leg 37 results indicate that the addition of vertical polarity layering and the presence of intrusive mélanges of layer 3 type rocks will be required in modeling in at least some areas.

\section{Lithologic and Magnetic Units}

The distribution of cleaned NRM inclinations of Figures 9 and 10 shows many well grouped sets of values over various depth intervals at all sites. Comparison of these intervals with the basement lithological units recognized at the sites generally shows excellent correlation. That is, the paleomagnetic data generally strongly support the identification of basement lithologic units, which is a result of geological significance in view of the commonplace low basement recovery, leaving a suspicion of unseen interunit contacts. The close relationship between magnetic and lithological units is specified quantitatively in Table 2 , in which stable NRM inclinations are subdivided into 55 groups containing two or more samples. The groups, with a small number of exceptions, are defined in terms of previously identified lithological divisions. The physical reality of this basis for subdivision is seen in the scatter associated with the 55 divisions; the average RMS error of the mean inclination for each subdivision is only $\pm 2.8^{\circ}$, this figure being comparable for the within-unit scatter of paleomagnetic directions for historic flows from Hawaii (Doell and Cox, 1963). In nine cases lithological units had to be subdivided to match changes in stable NRM inclination level. A further 22 lithological units were represented by only one paleomagnetic sample. The success of this correlation of stable NRM inclination with lithological units leads us to define the magnetic unit: with rare exceptions this is equivalent to lithologic units. The vertical extent of lithologic/magnetic units, and the small uncertainty involved in their definition, are shown in Figures 11 and 12. From these figures we see that the magnetic structure of uppermost basement at Sites 332 and 335 is dominated by a small number of well-defined magnetic units, ranging from less than a meter to at least 108 meters in thickness. Magnetic units are also seen at Sites 333 and 334 but are proportionally less important in basement construction. A further feature of importance evident from Figures 9 and 10 and Table 2 is the close similarity of average stable NRM inclination of many magnetic units. For example, Units 14 to
18 inclusive of Hole 332B all have average stable inclinations in the range of $-10.7^{\circ}$ to $-15.0^{\circ}$. Here and elsewhere the uncertainties associated with these averages are such that the average directions are statistically indistinguishable, or are nearly so. This leads us to define the magnetic superunit, which consists of a series of adjacent lithologic/magnetic units with statistically indistinguishable (or nearly so) average stable NRM inclinations. In as small number of instances magnetic superunits have been defined which encompass one or more aberrant inclinations, in particular odd normal inclinations in long shallow reversely magnetized sequences of units in Hole 332B. This is a reasonable step if it is assumed that the normally magnetized samples represent thin intrusions that considerably postdate the superunit. A total of 15 magnetic superunits has been identified, with a range and average thickness of 2 to 94 meters and 41 meters, respectively. The identification of magnetic superunits implies either that many lithologic units are in fact variants within single thicker units or that eruptive activity during layer 2 formation was highly episodic, with periods characterized by eruptions every few years followed in quiescent intervals of at least several hundred years and perhaps much longer.

\section{Correlation of Holes 332A and 332B}

One of the most striking and disconcerting paleomagnetic results from Holes $332 \mathrm{~A}$ and $332 \mathrm{~B}$, which are separated laterally by only 107 meters, is the clear differences between the profiles from the top of basement to a subbasement depth of close to 300 meters (Figure 13). In particular:

1) The uppermost 70 meters of basement in Hole $332 \mathrm{~A}$, consisting of three magnetic units, is normally magnetized;

2) Coarsely plagioclase-phyric basalts of closely similar macroscopic appearance form the uppermost major lithologic units in both Holes 332A and 332B (and occur nowhere else). However, these are of opposite polarities, $\mathrm{N}$ in $332 \mathrm{~A}$ and $\mathrm{R}$ in 332B.

3) Three shallow reversely magnetized units or superunits are identifiable at between 170 and 290 meters subbasement in Hole 332A. In the corresponding interval in Hole 332B only the lower part of one superunit, extending just to 204 meters subbasement, occurs.

4) Partly lithified nanno-foram ooze is associated with aphyric basalt at 257 meters subbasement in Hole $332 \mathrm{~A}$ and at 285 meters subbasement in Hole 332B. Nowhere else were such associations found. However, in Hole $332 \mathrm{~A}$ both ooze and basalt are normally magnetized, comprising a narrow $\mathrm{N}$ zone in a long sequence of shallow $\mathrm{R}$ units and samples, while in Hole 332B both ooze and basalt are shallow reversely magnetized, as are the adjacent magnetic units and samples.

Clearly then the basement profiles in Holes $332 \mathrm{~A}$ and $332 \mathrm{~B}$ to 300 meters subbasement are quite different, and can only partly be reconciled by the interpretation of the difference in uppermost basement depths as an erosional or depositional feature, with the $\mathrm{N}$ basalts of 
TABLE 2

Basement Paleomagnetic Samples, Units, and Superunits

\begin{tabular}{|c|c|c|c|c|c|c|c|c|c|}
\hline Site or Hole & $\begin{array}{l}\text { Lithological } \\
\text { Unit }\end{array}$ & $\begin{array}{r}\text { Mean Cleaned Paleomagr } \\
\text { Inclination for Unit } \\
\text { ( RMS Error on Mean }\end{array}$ & netic & $\begin{array}{l}\text { Number of Samples } \\
\text { Contributing to } \\
\text { Mean }\end{array}$ & $\begin{array}{l}\text { Mean Cleaned } \\
\text { Inclination fo } \\
\text { ( RMS Erro }\end{array}$ & $\begin{array}{l}\text { Paleomagnetic } \\
\text { or Superunit } \\
\text { or on Mean) }\end{array}$ & $\begin{array}{l}\text { Unit } \\
\text { Code }\end{array}$ & $\begin{array}{l}\text { Number of } \\
\text { Units Cont. } \\
\text { to Mean }\end{array}$ & $\begin{array}{l}\text { Depth Extent of Superunit } \\
\text { (Thickness, m, Subbottom) }\end{array}$ \\
\hline $332 \mathrm{~A}$ & 1 & & & 0 & & & & & \\
\hline (Lithologi- & 2 & $+29.5 \pm 0.7$ & & 3) & & & & & \\
\hline cal units & 3 & $+39.2 \pm 4.3$ & & $3\}$ & +32.9 & 3.1 & 2AM1 & 3 & $104-112(8)$ \\
\hline from Table 7, & 4 & $+30.1 \pm 1.3$ & & $2 J$ & & & & & \\
\hline Chapter 2, & 5 & $+70.4 \pm 1.5$ & & 3 & & & & & \\
\hline this volume) & 6 & $+53.7 \pm 5.4$ & & $2)$ & & & & & \\
\hline & 7 & +53.8 & & 1 & & & & & \\
\hline & 8 & & & 0 & & & & & \\
\hline & 9 & +49.4 & & 1 & & & & & \\
\hline & 10 & +49.4 & & 1 & & & & & \\
\hline & 11 & & & 0 & +52.8 & 1.8 & 2AM2 & 5 & $121-161(40)$ \\
\hline & 12 & & & 0 & & & & & \\
\hline & 13 & & & 0 & & & & & \\
\hline & 14 & & & 0 & & & & & \\
\hline & 15 & $+59.3,+35.0$ & & 2 & & & & & \\
\hline & 16 & $+58.5 \pm 1.1$ & & $3 \mathrm{~J}$ & & & & & \\
\hline & 17 & $-14.3 \pm 4.6$ & & $3)$ & & & & & \\
\hline & 18 & & & $0\}$ & $\begin{array}{ll}-09 & 4\end{array}$ & 4.7 & $2 \mathrm{AM} 3$ & 2 & $171-179(8)$ \\
\hline & 19.1 & -05 & & $1 J$ & & & & & \\
\hline & 19.2 & -67.3 & & 1 & & & & & \\
\hline & 19.3 & $-41.7 \quad 3.2$ & & 4 & & & & & \\
\hline & 20.1 & +24.9 & & (1) & -38.4 & 3.3 & $2 \mathrm{AM} 4$ & 2 & $237-274(37)$ \\
\hline & 20.2 & -35.20 .6 & & 2 & & & & & \\
\hline & 21 & & & 0 & & & & & \\
\hline & 22 & & & 0 & & & & & \\
\hline & 23 & 0 & & & & & & & \\
\hline & 24 & -26.0 & & $1]$ & & & & & \\
\hline & 25 & & & $0\}$ & -27.8 & 1.8 & 2AM5 & 2 & $292-294(2)$ \\
\hline & $26 . a$ & $-29.5 \pm 0.7$ & & $2 J$ & & & & & \\
\hline & 26.c.1 & -20.3 & & $1)$ & & & & & \\
\hline & 26.c. 2 & $-20.7 \pm 2.6$ & & 2 & & & & & \\
\hline & $27 . a$ & $-13.0 \pm 1.0$ & & 2 & & & & & \\
\hline & $\begin{array}{l}27 . b \\
28\end{array}$ & $-19.5 \pm 8.6$ & & $\begin{array}{l}2 \\
0\end{array}$ & & & & & \\
\hline & 29 & $-15.2 \pm 7.6$ & & 2 & -16.5 & 1.3 & 2AM6 & 11 & $303-397(94)$ \\
\hline & 30 & $-22.7 \pm 0.8$ & & 9 & & & & & \\
\hline & 31.1 & $-14.6 \pm 3.1$ & & 6 & & & & & \\
\hline & 31.2 & $-31.4 \pm 1.4$ & & 3 & & & & & \\
\hline & 32 & -19.9 & & 1 & & & & & \\
\hline & 33 & $-15.2 \pm 0.6$ & & 3 & & & & & \\
\hline & 34 & $-11.3 \pm 0.8$ & & 4 & & & & & \\
\hline & 35 & $\begin{array}{ll}-09 & 4\end{array}$ & & $2 J$ & & & & & \\
\hline & 36 & $-33.4 \pm 3.6$ & & 27 & & & & & \\
\hline & 37 & & & 0 & & & & & \\
\hline & 38 & & & 0 & & & $2 \mathrm{AM} 7$ & 3 & $398-429(31)$ \\
\hline & $\begin{array}{l}39 \\
40\end{array}$ & & & $\begin{array}{l}0 \\
0\end{array}$ & -27.0 & 3.7 & 2ก:บ1 & & \\
\hline & $\begin{array}{l}40 \\
41\end{array}$ & & $?$ & $\begin{array}{l}0 \\
0\end{array}$ & & & & & \\
\hline & 42 & -20.6 & & 51 & & & & & \\
\hline
\end{tabular}




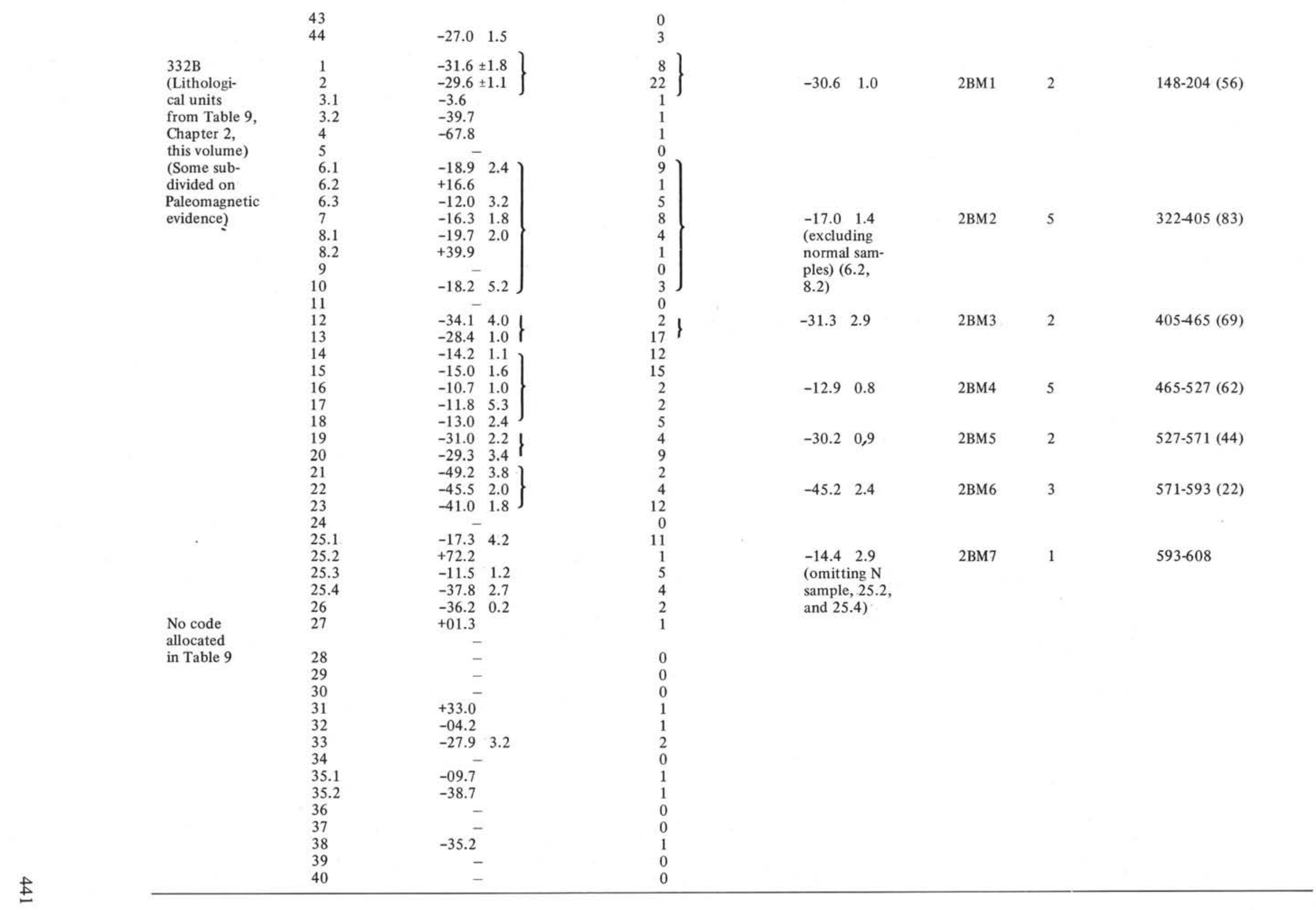


TABLE 2 - Continued

\begin{tabular}{|c|c|c|c|c|c|c|c|}
\hline Site or Hole & $\begin{array}{l}\text { Lithological } \\
\text { Unit }\end{array}$ & $\begin{array}{l}\text { Mean Cleaned Paleomagnetic } \\
\text { Inclination for Unit } \\
\text { (RMS Error on Mean) }\end{array}$ & $\begin{array}{l}\text { Number of Samples } \\
\text { Contributing to } \\
\text { Mean }\end{array}$ & $\begin{array}{l}\text { Mean Cleaned Paleomagnetic } \\
\text { Inclination for Superunit } \\
\text { RMS Error on Mean) }\end{array}$ & $\begin{array}{l}\text { Unit } \\
\text { Code }\end{array}$ & $\begin{array}{l}\text { Number of } \\
\text { Units Cont. } \\
\text { to Mean }\end{array}$ & $\begin{array}{l}\text { Depth Extent of Superunit } \\
\text { (Thickness, m, Subbottom) }\end{array}$ \\
\hline & 41 & $+01.4 \pm 5.9$ & 7 & & \multicolumn{3}{|l|}{ 2BM 8} \\
\hline & 43 & - & 0 & & \multirow{2}{*}{\multicolumn{3}{|c|}{$2 \mathrm{BM} 9$}} \\
\hline & 44 & $\begin{array}{ll}-28.1 & 2.2\end{array}$ & 5 & & & & \\
\hline $332 \mathrm{C}$ & 1 & $-34.7 \quad 4.0$ & 2 & & \multicolumn{3}{|l|}{ 2CM1 } \\
\hline 332D & 1 & +24.5 & 1 & & \multicolumn{3}{|l|}{ 2DM1 } \\
\hline \multirow{6}{*}{$333 \mathrm{~A}$} & 1 & \multicolumn{6}{|l|}{ Cleaned incli- } \\
\hline & 3 & \multicolumn{6}{|l|}{$\begin{array}{l}\text { nations scat- } \\
\text { tered, litholog- }\end{array}$} \\
\hline & 4 & \multicolumn{6}{|l|}{ ic units not sup- } \\
\hline & 5 & \multirow{2}{*}{\multicolumn{6}{|c|}{$\begin{array}{l}\text { ported by paleo- } \\
\text { magnetic evidence }\end{array}$}} \\
\hline & 6 & & & & & & \\
\hline & 8 & $+02.3 \quad 2.0$ & 6 & & \multicolumn{3}{|l|}{ 3AM1 } \\
\hline \multirow[t]{3}{*}{334} & 1 & $+50.0 \quad 4.0$ & 4 & \multirow[t]{2}{*}{$+53.1 \pm 3.1$} & \multirow[t]{2}{*}{$4 \mathrm{M} 1$} & \multirow[t]{2}{*}{2} & \multirow[t]{2}{*}{$260-311(49)$} \\
\hline & 2 & $+56.1 \quad 2.5$ & 14 & & & & \\
\hline & 3 & $\begin{array}{l}\text { Cleaned incli- } \\
\text { nations scat- } \\
\text { tered for plut- } \\
\text { onics of Unit } 3\end{array}$ & & & & & \\
\hline
\end{tabular}




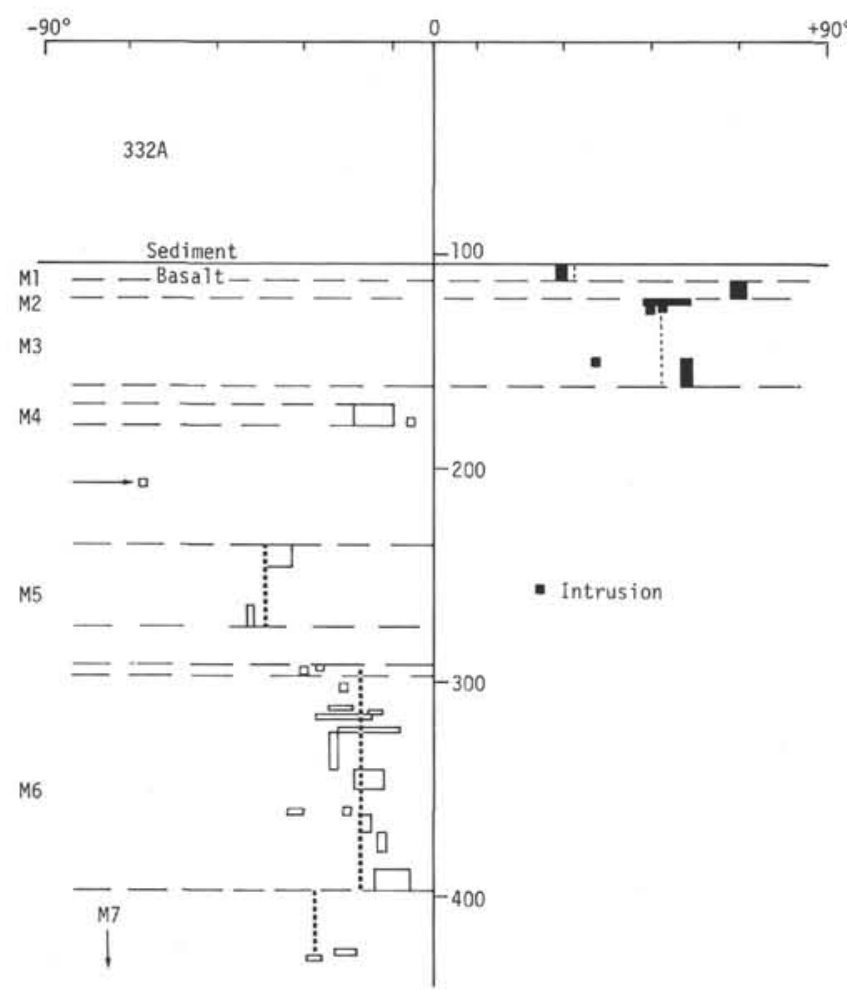

Figure 11a. Magnetic units and superunits, together with individual samples for Hole 332A. The length and width of a bar indicates, respectively, the depth extent of a magnetic unit and the standard deviation of the mean stable inclination for the unit. Broken vertical lines indicate the depth extent and mean stable inclination for superunits. Individual sample values are indicated by small squares.

Hole $332 \mathrm{~A}$ either eroded from or never deposited on the top of the Hole 332B succession.

However, at below 300 meters subbasement there is a strong resemblance in the sequences of magnetic superunits in the two holes, with superunits 2AM6 and 2AM7 of Hole $332 \mathrm{~A}$ agreeing closely in mean inclination $\left(-16.5 \pm 1.3^{\circ},-27.0 \pm 3.7^{\circ}\right)$ and thickness $(94 \mathrm{~m}, \geq$ $31 \mathrm{~m}$ ) with superunits $2 \mathrm{BM} 2$ and $2 \mathrm{BM} 3$ of Hole $332 \mathrm{~B}$ at $\left(-17.0 \pm 1.4^{\circ},-31.3 \pm 2.9^{\circ}\right)$ and $(83 \mathrm{~m}, 60 \mathrm{~m})$, respectively. These correlations closely match reported lithologic and geochemical correlations (this volume). The lack of paleomagnetic information for Hole 332B between 200 and 300 meters subbasement precludes comment on lithologic and geochemical correlations for this interval.

\section{Paleomagnetic Evidence for the Construction of Layer 2 at the Leg 37 Sites}

Several points concerning the construction of layer 2 can be derived from the stable NRM inclination data:

1) The importance of magnetic units and superunits implies that the uppermost part of layer 2 at the sites is often formed by a small number of eruptions or short eruptive episodes, probably lasting not more than a few tens of years. Consequently most of the $\sim 10^{5} \mathrm{yr}$ time interval required for the formation of layer 2 in the area is not represented by any rock units. For

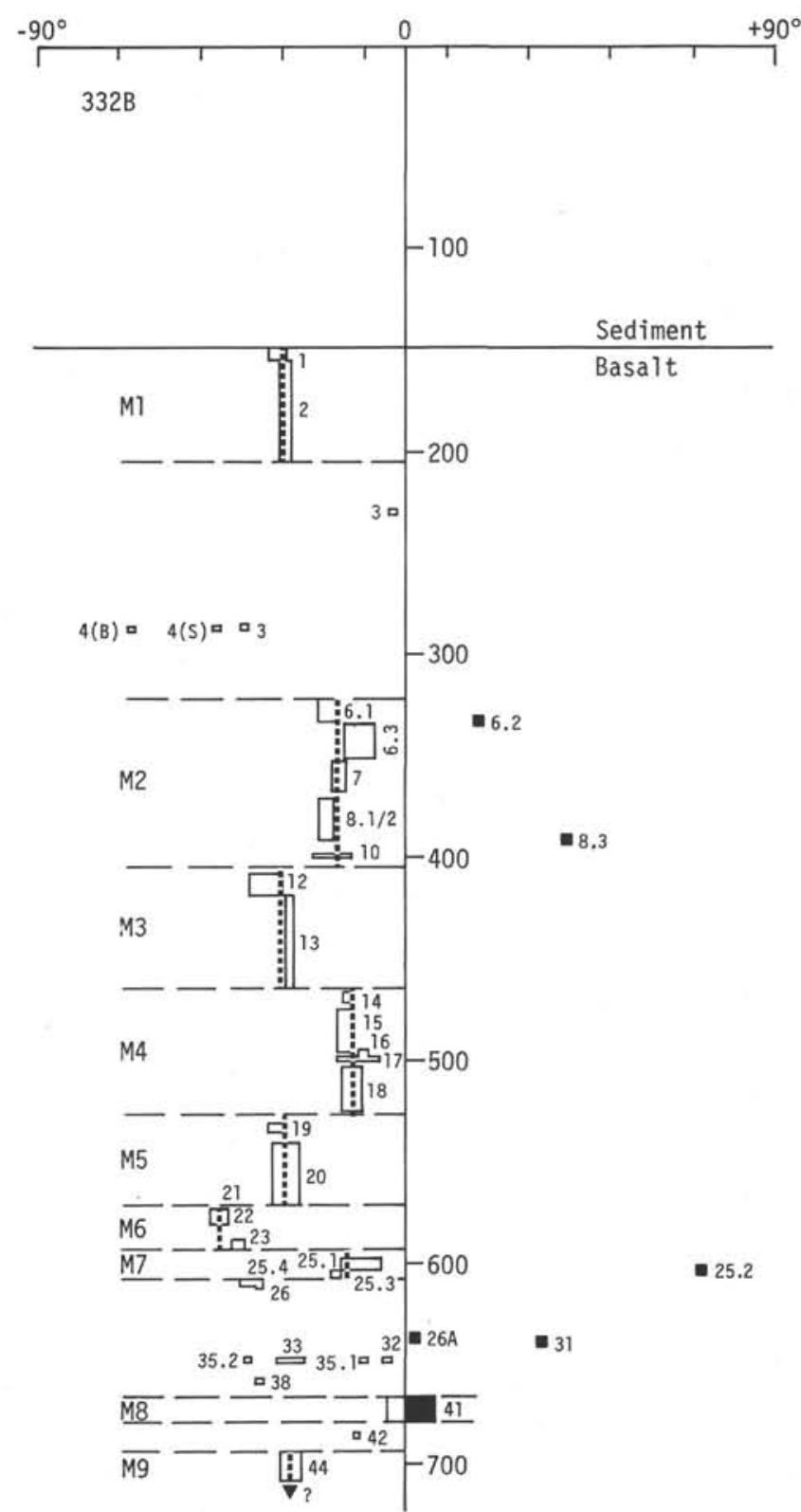

Figure 11b. Magnetic units and superunits, together with individual samples for Hole 332B. Symbols as in Figure $11 a$.

example, at least the uppermost 108 meters of layer 2 at Site 335 , comprising approximately $5 \%$ of an average layer 2 thickness, was formed during a single eruption or eruptive episode. Similarly, the 49-meter-thick basaltic sequence at Site 334 comprises a single magnetic superunit, requiring at most only a few tens of years for its accumulation. In Hole 332A, seven magnetic superunits, averaging 31 meters in thickness, total 220 meters or $68 \%$ of the section. Again, in Hole 332B nine superunits and thick magnetic units, averaging 41 meters in thickness, total 367 meters or $66 \%$ of the section.

The widespread nature of thick magnetic units or superunits suggests that the dominant contribution to the construction of a 2-km-thick layer 2 in the Leg 37 


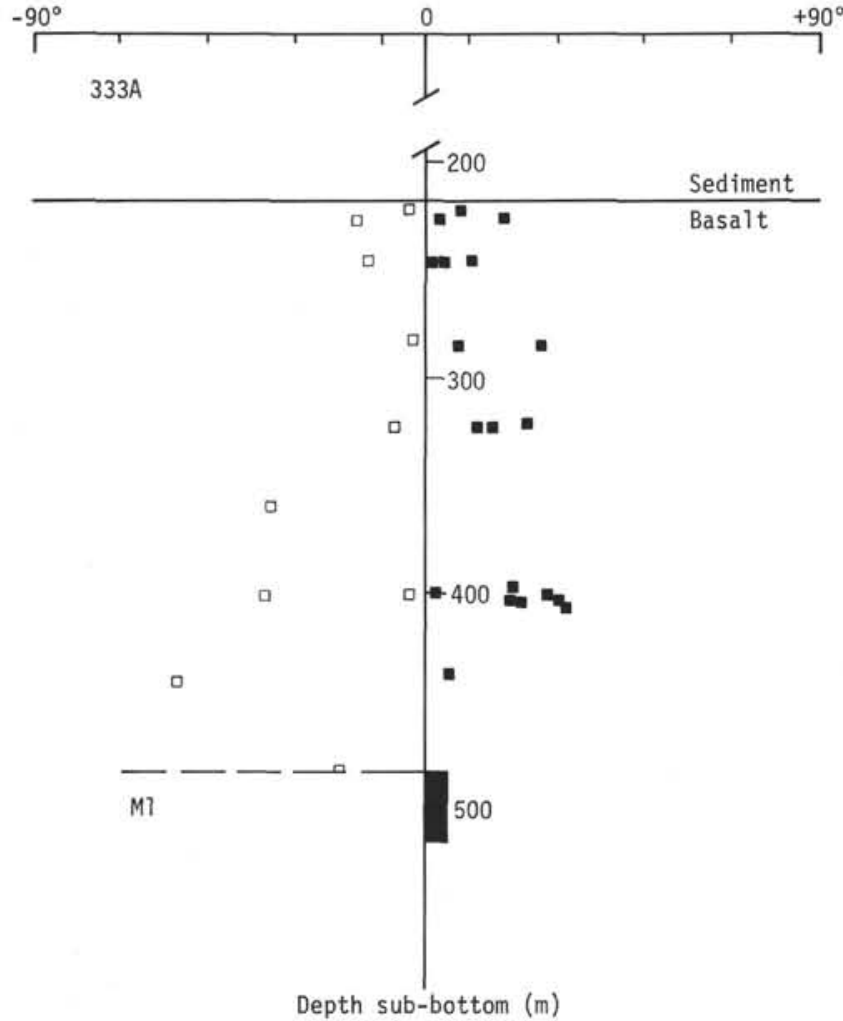

Figure 12a. Magnetic unit and individual samples for Hole $333 A$.

area are the products of some 20 or so eruptions or eruptive episodes. The average thickness of magnetic units and superunits is significantly more than the thickness of subaerial lavas which, in Iceland, for example, average 4.5 meters for 1100 measured flows (Dagley et al., 1967).

2) The presence of occasional samples with distinct Normal polarity throughout the basement sections at Site 332 suggests tnat minor intrusives are present in the basement sequences here. The close spacing of 10 meters or so, between Unit 1 of Hole 332D (an aphyric basalt, in apparent intrusive contact with indurated nanno ooze, and stable NRM inclination of $+24.5^{\circ}$ ), with the coarsely plagioclase phyric, shallow reversely magnetized basalts of Holes 332 B and 332C, appears to require an intrusive nature for the Hole 332D basalt.

Again, the cleaned NRM inclinations for the chalk recovered from Core 22 in Hole 332A, $\left(+61.6^{\circ}\right.$, $+34.1^{\circ}$ ) approach the cleaned NRM inclination of basalt intercalated in the chalk $\left(+24.9^{\circ}\right)$ as the basaltchalk contact is approached. This is a typical paleomagnetic relationship between a minor intrusive and the adjacent country rock.

Induration of sediments is to be expected in the vicinity of minor intrusives and the occasional recovery of chalk, representing indurated nanno-foram ooze, from within basement sections may be an indicator that one of the adjacent basalts is an intrusive. If this is the case then minor intrusives of both $\mathrm{N}$ and $\mathrm{R}$ polarities are present at Site 332. Thus, in Holes 332A, Core 22, and $332 \mathrm{D}$, normal polarity basalts occur with chalk while in Hole 332B, Core 6, reverse polarity chalk lies between basalts of reverse polarity.

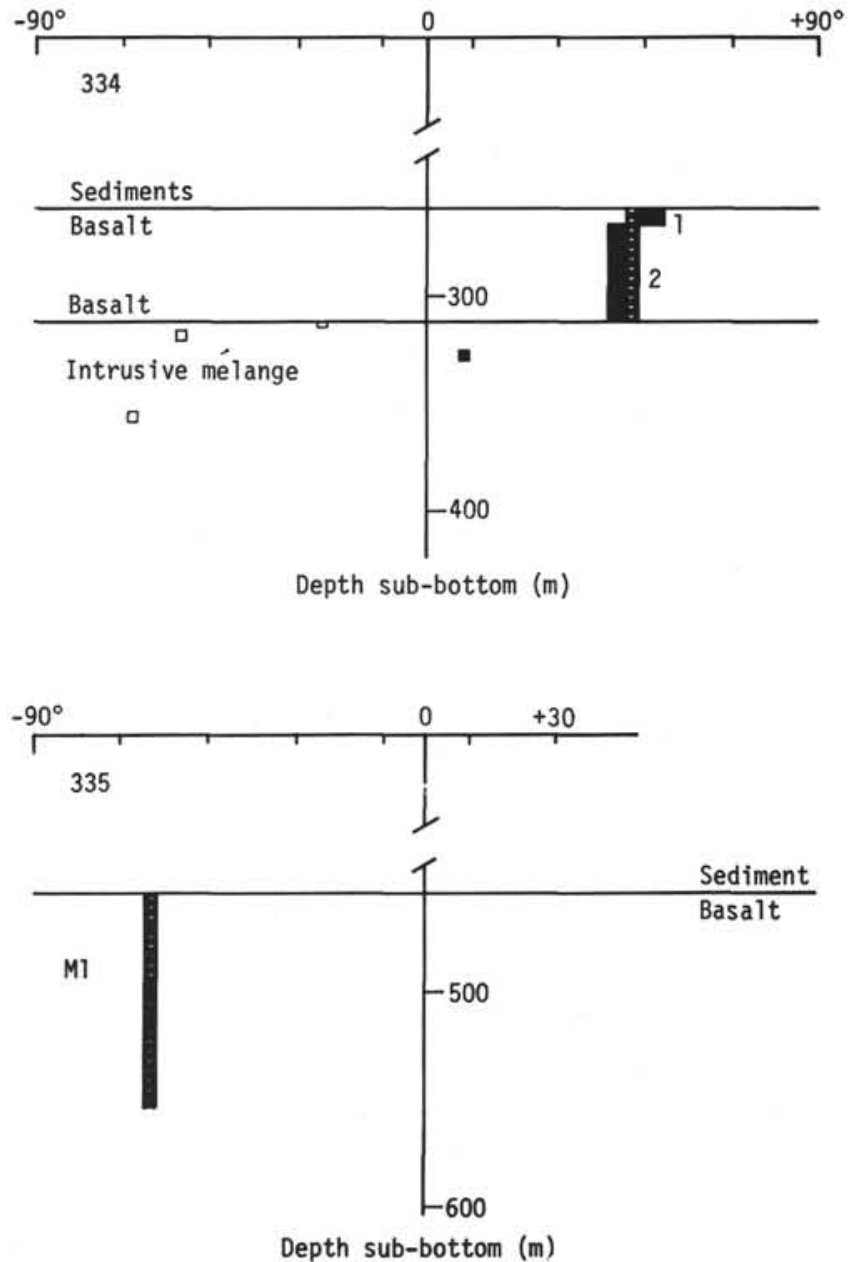

Figure 12b,c. Magnetic units, superunit, and individual samples for Site 334. (c) Magnetic unit for Site 335. The symbols used in Figure 12 are identical with those used in Figure 11.

\section{Paleomagnetic Inclinations and Absolute Plate Motion}

If the geomagnetic field is axially dipolar in form, then the paleolatitude of a basalt at the time of initial magnetization can be obtained from the relationship.

$$
\theta=\tan ^{-1}(1 / 2 \tan I)
$$

where $\theta$ is the paleolatitude and $I$ the stable NRM inclination. Thus we have in principle a simple means of estimating the net absolute latitudinal motion of a basalt since its time of initial cooling, and by association, the motion of the plate of which it forms part. In practice the drawback of the method is lack of knowledge of how well the paleomagnetic data represent a magnetic field of axial dipole form. Formerly, it has been assumed that given sufficient paleomagnetic data from a sequence of rocks, the average inclination will correspond with the dipole inclination. However, the episodic nature of subaerial volcanicity has recently been identified from paleomagnetic data (Wilson, 1970; Ade-Hall et al., 1975a) and the magnetic structure of layer 2 at the Leg 37 sites suggests that episodic volcanism is also a feature of submarine volcanic activity. If volcanism has been episodic then a simple average 


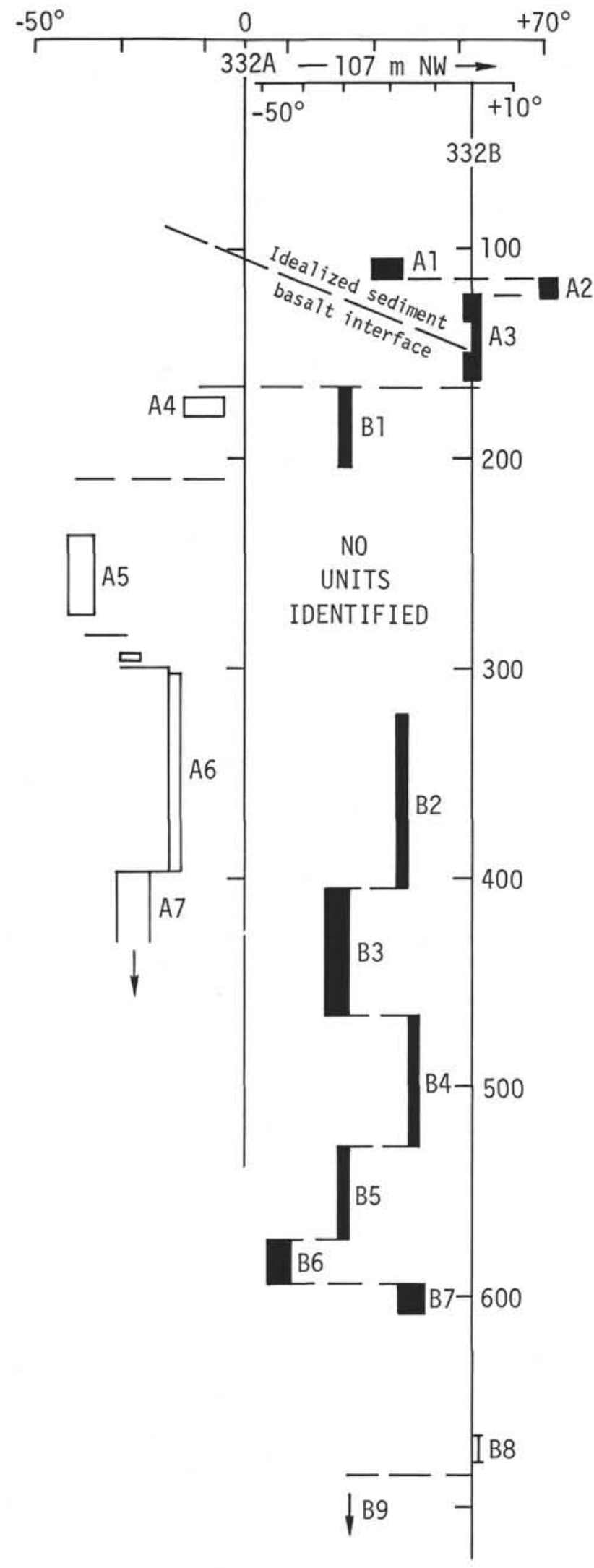

Figure 13. Comparison of the magnetic stratigraphy of Holes $332 A$ and 332B. Gray and black bars: magnetic units and superunits of Hole $332 \mathrm{~A}$ and Hole $332 \mathrm{~B}$, respectively. of paleomagnetic inclinations is unlikely to correspond to the average dipole inclination over the total eruptive interval. It follows that, unless the exact timing of eruptive events is known, the degree of departure of the average paleomagnetic inclination from the dipole field cannot be determined. These conclusions are well illustrated by the average stable inclinations for the Leg 37 sites (Table 3 ). The apparent plate motion for the two youngest sites is from 15 to 36 degrees northwards, with average apparent velocities of from $50 \mathrm{~cm} / \mathrm{yr}$ to $120 \mathrm{~cm} / \mathrm{yr}$. These velocities are from one to two orders of magnitude higher than absolute plate velocities determined by other means. For this reason they are very unlikely to be correct, and either tectonic or geomagnetic explanations, rather than plate motion, must account for the major part of the differences between observed and expected site-average inclinations. This conclusion is supported by the results from the two older sites, where, with only one magnetic unit or superunit at each site, very much smaller absolute plate motions are indicated.

\section{SUMMARY AND CONCLUSIONS}

The paleomagnetic results for the basement rocks recovered during DSDP Leg 37 fall into two groups; those which describe the present magnetic state of the uppermost quarter of oceanic crustal layer 2 and others which relate to the original magnetic state, and the tectonic and formational history of this part of layer 2 .

Basalt NRM intensities, giving unit weight to 9.5meter core lengths, average close to $40 \times 10^{-4}$ $\mathrm{emu} / \mathrm{cm}^{3}$. This is a relatively high intensity of magnetization compared with subaerial basalts but is much smaller than the values of between 100 and 1000 $\times 10^{-4} \mathrm{emu} / \mathrm{cm}^{3}$ observed for basalts obtained from ridge crests, which together with intensity estimates obtained by inverting anomaly data over topographic features close to ridge crests (Talwani et al., 1971; Atwater and Mudie, 1973) have given rise to the widespread acceptance of $100 \times 10^{-4} \mathrm{emu} / \mathrm{cm}^{3}(0.01 \mathrm{emu})$ as a representative value for a postulated magnetic anomaly source layer. The results from the Leg 37 basalts, and similar relatively low basalt average intensities found for other DSDP sites, indicate that $40 \times 10^{-4} \mathrm{emu} / \mathrm{cm}^{3}$ $(0.004)$, or even less if the presence of nonmagnetic sediment and rubble is assumed, is a more realistic value.

This result indicates that a uniformly magnetized anomaly source layer, if such exists, must be appreciably thicker than the 400-500 meters used with an assumed intensity of $100 \times 10^{-4} \mathrm{emu} / \mathrm{cm}^{3}$. The fact that NRM intensity does not show any trend with depth over subbasement depths of from 108 to 582 meters at the Leg 37 sites supports this conclusion.

Previous models of the magnetism of oceanic layer 2 have assumed that magnetic directions matched either the normal or reverse directions of the geomagnetic field. In fact, at three of five Leg 37 holes this is far from true, magnetic inclinations being strongly biased towards the horizontal, being well away from the ideal dipole values of $\pm 56^{\circ}$ for the area. This bias is partly the result of the addition of soft normal viscous magnetization to originally reversely magnetized rocks but is primarily the result of stable NRMs having 
TABLE 3

Site Average Basalt Stable Paleomagnetic Inclinations and

Corresponding Apparent Paleolatitudes and Present Latitudes

\begin{tabular}{|c|c|c|c|c|c|c|}
\hline \multirow{3}{*}{$\begin{array}{c}\text { Site or Hole } \\
332 \mathrm{~A} \\
332 \mathrm{~B}\end{array}$} & \multirow{2}{*}{$\begin{array}{c}\text { Average Based on } \\
\text { Magnetic Units and } \\
\text { Superunits Only }\end{array}$} & \multirow{2}{*}{\multicolumn{3}{|c|}{$\begin{array}{c}\begin{array}{c}\text { Average Based on } \\
\text { Magnetic Units, } \\
\text { Superunits, and } \\
\text { Individual Samples }\end{array} \\
37.7 \pm 6.0^{\mathrm{d}}\end{array}$}} & \multicolumn{2}{|c|}{${ }^{\theta_{\mathrm{P}}}{ }^{\mathrm{a}} \theta_{\mathrm{L}}^{\mathrm{b}} \Delta \theta_{2}{ }^{\mathrm{c}}$} \\
\hline & & & & & $21.1 \pm 4.4$ & $36.9+15.8$ \\
\hline & $-23.1 \pm 4.6$ & $12.0 \pm 2.7$ & $36.9+24.9$ & $27.5 \pm 3.7$ & $14.6 \pm 2.3$ & $36.9+22.3$ \\
\hline $333 \mathrm{~A}$ & $+02.3 \pm 2.0$ & $1.2 \pm 1.0$ & $36.9+35.7$ & $15.5 \pm 3.0$ & $7.9 \pm 1.6$ & $36.9+29.0$ \\
\hline 334 & $+53.1 \pm 3.1$ & $33.7^{ \pm} 3.0$ & $37.0+3.3$ & $+53.1 \pm 3.1$ & $33.7 \pm 3.0$ & $37.0+3.3$ \\
\hline 335 & $-63.5 \pm 1.1$ & $45.1 \pm 1.4$ & $37.3-7.8$ & $-63.5 \pm 1.1$ & $45.1 \pm 1.4$ & $37.3-7.8$ \\
\hline
\end{tabular}

aApparent paleolatitude of site $\left({ }^{\circ} \mathrm{N}\right)$.

bPresent latitude of site $\left({ }^{\circ} \mathrm{N}\right)$.

$\mathrm{c}_{\Delta \theta}=$ Present latitude of site - paleolatitude of site $\left.{ }^{\circ}\right)$.

$\mathrm{d}$ Average obtained on the assumption that polarity is reliably indicated by the sense of the inclination.

anomalously shallow inclinations. This result does not match the predictions of the Vine-Matthews hypothesis, which is also violated by the presence of both normally and reversely magnetized basalts in vertical sections through layer 2. So far as magnetic layer thicknesses are concerned, both shallow NRM inclinations and polarity interleaving have the effect of reducing the effective magnetization of the layer, so requiring greater thicknesses to produce observed anomalies. Thus, while we calculate that magnetic layer thickness of from 570 to 820 meters will suffice where uniform magnetization at near ideal dipole inclinations occurs, layer thickness would have to exceed $2.5 \mathrm{~km}$ where shallow inclinations and polarity interleaving occurs. In essence, suitable magnetic sources were not found in the deep holes of Sites 332 and 333. If sources are present at these localities they must either be buried at greater than 600 meters beneath the upper surface of layer 2 or the declinations of shallow inclined NRMs must be far from the magnetic meridian, that is, extending the degree of nonideal dipole magnetization of the basalts.

NRM intensities for the plutonic components of the mélange encountered at Site 334 vary from values comparable to the basalts (for serpentinized peridotites) to three orders weaker (for fresh gabbros). It is conceivable that serpentinized peridotites at greater depths may contribute towards the magnetic anomaly not only at Site 334, but at other sites as well.

For the basalts induced magnetization is always much less than remanence, matching experience with almost all other submarine basalts. For the plutonic components of the mélange at Site 334 induced magnetization is relatively more important than for the basalts, but only exceeds remanence in one of six samples.

There is abundant magnetic information contained in the basalts in addition to NRM and induced magnetization properties. This extra information is obtained by remanence analysis, which in our case has been achieved by partial alternating-field demagnetization. This operation, which has been carried out routinely to 500-oe peak field on all basement samples, allows soft and stable NRM components to be isolated. These in turn relate to the acquisition of magnetization at ambient temperatures, probably through the viscous process, and to the original magnetization of the basalt through the thermoremanence process. The necessity for routine remanence analysis is indicated by the fact that for almost half the samples significant soft components were isolated. With rare exceptions these soft components match the downwards sense of the present field and are interpreted as viscous moments acquired over the last $7 \times 10^{5} \mathrm{yr}$. The stable NRM components remaining after the removal of the soft components have two interesting properties. Firstly the scattered shallow undemagnetized NRM inclinations of Sites 332 and 333 are seen largely to consist of shallow reverse inclinations. These shallow stable NRM inclinations deviate significantly from the range of secular variation about the ideal dipole field. Secondly, stable NRM inclinations are well grouped over long basement sections.

Shallow stable NRM inclinations present a major problem. They may be explained in several ways, none of which is presently convincing. Postoriginal magnetization tectonic tilting is a possibility, however large $\left(30^{\circ}\right.$ to $\left.40^{\circ}\right)$ dips to the south are required whereas so far as is known only small $\left(3^{\circ}-10^{\circ}\right)$ dips to the west occur in the vicinity. Recording of an excursion of the geomagnetic field by the basalt sequence is an alternative explanation. The extent of shallow directions seems on statistical grounds to preclude the excursion being a polarity transition. It seems necessary to invoke a longer term departure from the axial dipole field. However, the existence of commonplace long-term departures is still a matter of controversy.

Although the many shallow reverse inclinations cannot be satisfactorily explained, the pattern of their occurrence does provide important information on the manner in which layer 2 has been constructed in the vicinity of the Leg 37 sites. First we note that welldefined stable NRM groupings (magnetic units) match very satisfactorily petrologic units. In addition, over a number of depth intervals, several adjacent lithologic magnetic units have statistically identical, or nearly so, average stable inclinations. These we call "magnetic superunits." The existence of magnetic units and superunits indicates that volcanism producing layer 2 at the Leg 37 sites was characteristically episodic, with 
single eruptions or short eruptive sequences of not more than $10^{2} \mathrm{yr}$ producing 100 meters or more of layer 2 , followed by intervals of $10^{3} \mathrm{yr}$ or greater without activity. We conclude that the major part of a typical 2$\mathrm{km}$-thick layer 2 section in the Leg 37 area is formed largely by the products of about 20 eruptions or eruptive sequences, implying that most of the total time for production of a layer 2 section is not represented among the rock units forming the layer.

The occurrence of scattered $\mathrm{N}$ inclinations among the shallow R units of Holes $332 \mathrm{~A}$ and $332 \mathrm{~B}$ suggests that at this site at least minor intrusives contribute a small part of the uppermost 580 meters of basement.

Further information on the construction and history of layer 2 at Site 332 is seen in the paleomagnetic (and petrographic and geochemical) differences between the uppermost sections at the two holes situated only 107 meters apart. Local nondeposition, erosion, or a tectonic break are required to reconcile these very different sections. In contrast, the lower part of the Site 332 basement sections correlate well, magnetically, petrographically, and geochemically.

A consequence of the frequent occurrence of shallow stable basalt NRM inclinations together with episodic volcanicity at the Leg 37 sites is that attempts to obtain absolute plate motion from the paleomagnetic results are unjustified.

The major problems arising from the paleomagnetic results from layer 2 at the Leg 37 sites are:

1) How is the source of the linear magnetic anomalies distributed through oceanic crust? Clearly the preferred model of a 400-500 meter thick uppermost layer 2 sheet, with strong $\left(100 \times 10^{-4} \mathrm{emu} / \mathrm{cm}^{3}\right)$ uniform magnetization with dipole directions is no longer generally tenable.

2) What is the explanation for the many very shallow stable NRM inclinations encountered?

\section{ACKNOWLEDGMENTS}

Many people contributed to the success of the paleomagnetic studies of Leg 37 basement rocks, in particular, the Captain, crew, drilling, scientific, and technical teams aboard Glomar Challenger; Jeff Clarke, Tim Milligan, Lata Hall, and Glen Johnson at Dalhousie University; David Ross and S.P. Srivastava at the Bedford Institute. Drafting was by Jan Aumento. Mary-Ann Annand and Ruth Feldbauer typed the manuscript. Paul Johnson, Bill Melson, and John Pierce read critically the first draft of this chapter.

We would like to offer our thanks to all these friends and colleagues.

\section{REFERENCES}

Ade-Hall, J.M., et al., 1975a. Sources of magnetic anomalies on the Mid-Atlantic Ridge: Nature, v. 255, p. 389-390.

Ade-Hall, J.M., Gerstein, S., Gerstein, R., Reynolds, P., Dayley, P., Mussett, A., and Hubbard, T., 1975b. Geophysical studies of North African Cenozoic volcanic areas; III: Garian, Libya: Canadian J. Earth Sci., v. 12, p. 12631271 .

Ade-Hall, J.M. and Johnson, H.P, 1976a. Paleomagnetism of basalts, Leg 34. In Hart, S.R., Yeats, R.S., et al., Initial Reports of the Deep Sea Drilling Project, Volume 34: Washington (U.S. Government Printing Office), p. 513532. 1976b. Review of magnetic properties of basalts and sediments, Leg 34. In Hart, S.R., Yeats, R.S., et al., Initial Reports of the Deep Sea Drilling Project, Volume 34: Washington (U.S. Government Printing Office) p. $769-778$.

Atwater, T. and Mudie, J.D., 1973. A detailed near bottom geophysical study of the Gorda Rise: J. Geophys. Res., v. 78 , p. $8665-8686$.

Carmichael, C.M., 1970 . The Mid-Atlantic Ridge near $45^{\circ} \mathrm{N}$. VII. Magnetic properties and opaque mineralogy of dredged samples: Canadian J. Earth Sci., v. 7, p. 239-256.

Dagley, P., et al., 1967. Geomagnetic polarity zones for Icelandic lavas: Nature, v. 216, p. 25-29.

Doell, R.R. and Cox, A., 1963. The accuracy of the paleomagnetic method as evaluated from historic Hawaiian lava flows: J. Geophys. Res., v. 68, p. $1997-$ 2009.

Heirtzler, J.R., Dickson, G.O., Herron, E.M., Pitman, W.C., and Le Pichon, X., 1968. Marine magnetic anomalies, geomagnetic field reversals, and motions of the ocean floor and continents: J. Geophys. Res., v. 73, p. 2119-2136.

Irving, E., Park, J.K., Haggerty, S.E., Aumento, F., and Loncarevic, B., 1970. Magnetism and opaque mineralogy of basalts from the Mid-Atlantic Ridge: Nature, v. 228, p. 974-976.

Johnson, H.P. and Ade-Hall, J.M., 1975. Magnetic results from basalts and sediments from the Nazca plate: DSDP Leg 34: Nature, v. 257, p. 471-473.

in preparation. Leg 34 . Rock magnetism of basalts.

Johnson, H.P. and Merrill, R.T., 1973. Low temperature oxidation of a titanomagnetite and the implications for paleomagnetism: J. Geophys. Res., v. 78, p. 4938-4949.

Lawley, E.A., 1970. The intensity of the geomagnetic field in Iceland during Neogene polarity transitions and systematic deviations: Earth Planet. Sci. Lett., v. 10, p. 145149.

Lowrie, W., 1974. Oceanic basalt magnetic properties and the Vine and Matthews hypothesis: J. Geophys., v. 40, p. 513-536.

Lowrie, W., L $\phi$ vlie, R., and Opdyke, N.D., 1973. The magnetic properties of Deep Sea Drilling Project basalts from the Atlantic Ocean: Earth Planet. Sci. Lett., v. 17, p. 338-349.

Marshall, M. and Cox, A., 1971a. Effect of oxidation on the natural remanent magnetization of titanomagnetite in suboceanic basalt: Nature, v. 230, p. 28-31.

1971b. Magnetism and pillow basalts and their petrology: Geol. Soc. Am. Bull., v. 82, p. 537-552.

Macdonald, K., Luyendyk, B.P., Mudie, J.D., and Spiess, E.N., 1975. Near bottom geophysical study of the MidAtlantic Ridge median valley near Lat. $37^{\circ} \mathrm{N}$ : Preliminary observations: Geology, v. 3, p. 211-215.

Ryall, P.J.C. and Ade-Hall, J.M., 1975. Radial variation of magnetic properties in basalt pillows dredged from the Median Valley of the Mid-Atlantic Ridge at $45^{\circ} \mathrm{N}$ : Canadian J. Earth Sci., v. 12, p. 1959-1969.

in preparation. Viscous magnetization of DSDP Leg 37 basement rocks.

Sclater, J.G. and Klitgord, K.D., 1973. A detailed heat flow, topographic and magnetic survey across the Galapagos spreading center at $86^{\circ} \mathrm{W}$ : J. Geophys. Res., v. 78 , p. 6951-6975.

Talwani, M., Windisch, C.C., and Langseth, M.G., 1971. Reykjanes Ridge Crest: A detailed geophysical survey: J. Geophys. Res., v. 78, p. 473-517.

Vine, F.J. and Matthews, D.H., 1963. Magnetic anomalies over ocean ridges: Nature, v. 199, p. 947-949.

Wilson, R.L., 1970. Paleomagnetic stratigraphy of Tertiary lavas from Northern Ireland: Geophys. J., v. 20, p. 1-10. 
Wilson, R.L. and McElhinny, M.W., 1974. Investigation of the large scale paleomagnetic field over the past 25 million years. Eastward shift of the Icelandic spreading ridge: Geophys. J., v. 39, p. 570-586.
Wilson, R.L., Dagley, P., and McCormack, A.G., 1972. Paleomagnetic evidence about the source of the geomagnetic field: Geophys. J., v. 28, p. 213-224. 